\title{
Thermogravimetric measurement of the equilibrium vapour pressure: application to water and triethanolamine.
}

\author{
Imen Zghal ${ }^{1,2}$, Jordi Farjas ${ }^{1}$, Jaume Camps ${ }^{1}$, Mohamed Dammak ${ }^{2}$, Pere Roura ${ }^{1}$. \\ ${ }^{1}$ University of Girona, Campus Montilivi, Edif. PII, E17071 Girona, Catalonia, Spain \\ ${ }^{2}$ Laboratoire de Chimie Inorganique, Faculté des Sciences de Sfax, University of Sfax, \\ BP 1171, 3000 Sfax, Tunisia
}

\begin{abstract}
A model that describes the pure evaporation kinetics is introduced. This model takes into account gas diffusion and convective gas transport; it describes the evaporation kinetics under the general conditions of thermogravimetric measurements. The model is used to determine the equilibrium vapour pressure in a relatively wide temperature range. The validity of the model is checked against experimental data of triethanolamine (TEA) and water evaporation. The applicability of isoconversional methods to the evaporation kinetics is also studied. Besides, it is shown that the degree of TEA decomposition depends on the surrounding atmosphere and on the conditions for gas evaporation; the easiest the gas evaporation, the smallest the degree of decomposition. In view of the volatiles formed, a reaction pathway is proposed for the thermal decomposition of TEA.
\end{abstract}

Keywords: Equilibrium vapour pressure, triethanolamine vapour pressure, water vapour pressure, evaporation model, thermogravimetric analysis of evaporation.

*Corresponding author: jordi.farjas@udg.edu, Tel (34)972418490, Fax (34) 972418098 University of Girona, Campus Montilivi, Edif. PII, E17071 Girona, Catalonia, Spain 


\section{Introduction}

Thermogravimetry (TG) is especially suited to analyse vaporization and sublimation processes. Thus, a realistic model that describes the evaporation kinetics in terms of the system parameters (sample mass, gas flow, furnace geometry and sample geometry) is useful to characterize the kinetics of the evaporation process itself but, also, to gain a better insight into the evaporation process under the typical running conditions of a TG apparatus.

The rate of evaporation of a liquid placed inside a cylindrical crucible which is immersed in a flowing gas can be understood by considering three steps coupled in series: a) lack of equilibrium at the liquid vapour-interface, b) diffusive transport inside the crucible and c) vapour carried away by the purge gas flow. The evaporation rate at the interface depends on the balance between the vapour molecules impinging on the liquid surface and those that escape from the liquid. Based on the kinetic theory of gases and following the work of Langmuir [1] Knudsen established that [2,3]:

$$
-\left.\frac{d m}{d t}\right|_{\text {liquid suf }}=\varepsilon S\left(\frac{M}{2 \pi R T}\right)^{1 / 2}\left(P_{S}-P_{0}\right),
$$

where $m$ is the mass of the liquid, $M$ the molecular mass, $T$ the temperature, $R$ the gas constant, $S$ is the crucible cross section area, $P_{S}$ and $P_{0}$ the equilibrium vapour pressure and the actual vapour pressure, respectively, and $\varepsilon$ the vaporisation coefficient (very close to unity [3]). The (-) sign in Eq. (1) means that the liquid mass diminishes. At the steady-state, the diffusion transport is given by:

$$
-\left.\frac{d m}{d t}\right|_{\text {diff }}=D S \frac{c_{0}-c_{h}}{h},
$$

where $h$ is the distance from the liquid surface to the crucible open end, $D$ is the vapour diffusivity, and $c_{i}$ are the vapour concentrations at the liquid surface and at the crucible open end, respectively. The vapour concentration is related to its partial pressure according to:

$$
c_{i}=\frac{P_{i} M}{R T}
$$

Finally, the vapour carried away by the purge gas will be proportional to the concentration and the purge gas velocity, $v$,

$$
-\left.\frac{d m}{d t}\right|_{c a}=S_{i} v c_{h},
$$


where $S_{i}$ is a cross-section to be defined later. These three steps give rise to the vapour pressure profile depicted in Figure 1.

Unless evaporation occurs in vacuum, the model can be simplified because, at the liquid surface, $P_{0} \approx P_{s}$; usually, $\left(P_{s}-P_{0}\right) / P_{s}<10^{-3}$ [3]. In other words, evaporation occurs with the liquid and vapour phases very close to equilibrium at the interface. Several authors have considered just the opposite condition (i.e. $P_{0}=0$ ) to analyse the evaporation into a gas [4-9]. This erroneous condition delivers unrealistic values of the evaporation coefficient $\varepsilon$ of the order of $10^{-4}-10^{-5}[5,10-12]$.

The analysis of evaporation involving steps $b$ and $c$ only has been successfully applied by Beverley et al. [13] to a TG with a vertical furnace (i.e. with the gas flowing parallel to the container axis). These authors obtained accurate values of the saturated vapour pressure of water and several organic liquids at room temperature. Its application to a horizontal furnace by Parker and Babas [19] also delivered reliable results. Although these authors developed their models within a mixed control regime, the values of $P S$ were obtained in the limit of diffusion-limited evaporation where $c_{o} \approx$ $c_{s}$ and $c_{h} \approx 0$. The diffusion-limited regime is achieved at low $v$ or for long diffusion paths (large values of $h$ ); see, also, refs. [16-18]. Consequently, these models have not been tested for short crucibles or in the limit of a liquid film $(h=0)$, where the vapour swept off by the purge gas is relevant or is the rate-controlling step.

The present paper deals with the evaporation kinetics in a horizontal furnace for crucibles and for films. It will be shown that, in this regime, the equation describing the vapour carried away has to be modified to account for the actual experimental behaviour. Another significant contribution is the determination of the vapour pressure from TG measurements performed on films and at a constant heating rate. Compared with the isothermal experiments of refs. [14,15], our method has several advantages. First, it allows exploring lower temperatures and a larger temperature interval. Second and thanks to the high surface to thickness aspect ratio, liquid cooling related to its evaporation can be neglected $[19,20]$; there is no need to correct deviations of the sample temperature [15]. Finally, the determination of $P_{S}$ is straightforward; the model is quite simple and few physical parameters are involved. Our method will be validated with water and then applied to the evaporation of triethanolamine (TEA).

TG experiments carried at constant heating rate are very suited to perform kinetic analyses such as isoconversional [21-24] and Kissinger [25] methods to obtain 
the activation energy of the process. We will analyse the limitations of using these methods to determine the evaporation enthalpy.

Finally we will test if evaporation of TEA is influenced or not by its thermal decomposition. To this aim the volatiles formed during TEA decomposition will be analysed. This is an important subject because TEA solutions are widely used in the gas processing industry for removing carbon dioxide and hydrogen sulphide from light hydrocarbons and in general to capture carbon dioxide [26]. $\mathrm{CO}_{2}$ removal by TEA occurs through a reversible reaction that involves the formation of a carbamate and bicarbonate. TEA is also used as complexing agent for metal oxide precursors [27-30]. Additionally, TEA is extensively used in chemical solution deposition methods to synthetize functional oxide thin films [31]; for instance, TEA is used as ligand for complexation and gel formation [32] and as complexing agent in solutions containing metal organic salts [33-35].

\section{Experimental details and methods}

\subsection{Material and thermal analysis techniques}

TEA (99\%) was purchased from Merck Co. and used without further purification. Purified Milli-Q water has been used for water evaporation measurements.

TGA analysis was performed with a Mettler Toledo thermobalance model TGA/DSC1. Temperature is calibrated using two calibration points (indium and aluminium melting points) and three different heating rates to correct tau lag deviations of the sample temperature. To minimize systematic baseline deviations a second measurement performed under identical conditions but with empty crucibles (or substrates) is subtracted. TEA was placed over a square $\left(10 \times 10 \mathrm{~mm}^{2}\right.$ or $\left.5 \times 5 \mathrm{~mm}^{2}\right)$ lanthanum aluminium oxide (LAO) substrate or inside alumina crucibles $\left(150 \mathrm{~mm}^{3}\right.$ capacity, 38.5 $\mathrm{mm}^{2}$ area and height $4 \mathrm{~mm}$ ). Most experiments where performed heating the sample at constant rate of $10 \mathrm{~K} / \mathrm{min}$, but experiments used to determine the vapour pressure and for the kinetic analysis were performed at six heating rates ranging from 1.2 to 40 $\mathrm{K} / \mathrm{min}$ to cover a wide temperature range [36]. Inside the TGA a gas flow rate of 10 to $40 \mathrm{~cm}^{3} / \mathrm{min}$ was controlled by mass flow meters. High-purity nitrogen, oxygen and argon were used. As we will see in the next section, a low purge flow rate is preferable because it allows getting closer to the condition of homegeneous vapour dilution. 
FTIR evolved gas analysis (FTIR-EGA) was performed with a Brucker model alpha spectrometer coupled to an attenuated total reflection (ATR) cell (model Platinum ATR). Wavenumber resolution is set to $4 \mathrm{~cm}^{-1}$. Each spectrum is the result of the average of 24 scans. Under these conditions, the acquisition of an IR spectrum takes approximately $30 \mathrm{~s}$. A $50 \mathrm{~cm}$ long steel tube was used to transfer the gases from the TGA furnace to the ATR cell. To prevent gas condensation the ATR cell and the steel tube were kept at a temperature of $200^{\circ} \mathrm{C}$.

\subsection{Kinetic methods}

The advanced isoconversional and Friedman methods are used to determine the activation energy [37-40]. Isoconversional methods rely on the hypothesis that, at a given $\alpha$, the transformation rate is only a function of temperature [41,42],

$$
\left[\frac{d \ln (d \alpha / d t)}{d T^{-1}}\right]_{\alpha}=-\frac{E_{\alpha}}{R}
$$

where $\alpha$ is the degree of transformation, $T$ is the temperature, $R$ is the gas constant, and $E_{\alpha}$ is the activation energy. The transformation rate can be obtained from the integration of Eq. (5) with respect 1/T,

$$
\frac{d \alpha}{d t}=A \exp \left[-\frac{E_{\alpha}}{R T}\right] f(\alpha),
$$

i.e., the isoconversional principle assumes that the transformation is governed by a rate constant, $k_{\alpha}(T)=A \exp \left[-E_{\alpha} / R T\right]$, that depends on $\alpha$ and $\mathrm{f}(\alpha)$ is a "kinetic function" that accounts for the dependence of the integration constant on $\alpha$. The variation of $E_{\alpha}$ with $\alpha$ is usually related to the occurrence of complex transformations. In this context, Eq. (6) is approximate and $E_{\alpha}$ must be interpreted as an apparent activation energy.

Besides, most kinetic methods rely on a set of measurements performed at different heating rates, $\beta=d \alpha / d T$. Under this condition, Eq. (6) may be expressed as,

$$
\frac{d \alpha}{d T}=\frac{A_{\alpha}}{\beta} \exp \left[-\frac{E_{\alpha}}{R T}\right] f(\alpha) \text {. }
$$

For instance, Kissinger method is based on the determination of the peak temperature, $T_{M}$, of a set of non-isothermal experiments [43]. $T_{M}$ is the temperature at which the transformation rate is at its maximum and can be obtained from the local maximum or minima of the calorimetric differential curve (DTA or DSC) or from the differential thermogravimetric curve (dTG). In our case $T_{M}$ has been determined from the dTG curves. 
If we assume that the transformation is ruled by a single mechanism and that the transformation rate is given by the Arrhenius equation, then the transformation rate is described by $[44,45]$ :

$$
\frac{d \alpha}{d t}=A \exp \left[-\frac{E}{R T}\right] f(\alpha),
$$

Contrarily to Eq. (6), in Eq. (8) $E$ and $A$ are constant and independent of $\alpha$. From Eq. (8) one can easily derive the Kissinger equation [36] that relates $T_{M}$ with the kinetic parameters:

$$
\ln \left(\frac{\beta}{T_{M}^{2}}\right)=-\frac{E}{R T_{M}}+\ln \left(-\frac{A R}{E} f^{\prime}\left(\alpha_{M}\right)\right),
$$

where $\beta$ is the heating rate, $f^{\prime}\left(\alpha_{M}\right) \equiv d f /\left.d \alpha\right|_{\alpha=\alpha_{M}}$ and $\alpha_{M}$ is the degree of transformation at $T_{M}$. Kissinger method relies on the determination of the peak temperature $T_{M, i}$ from experiments carried out at different heating rates $\beta_{i}$ and delivers the activation energy from a linear fit of the plot $\ln \left(\beta_{i} / T_{M, i}^{2}\right)$ versus $1 / T_{M, i}$.

In TGA measurements, it is commonly assumed that the degree of transformation depends linearly on the mass evolution:

$$
\alpha(t)=\frac{m_{\text {in }}-m(t)}{m_{\text {in }}-m_{\text {fin }}},
$$

where $m_{i n}$ and $m_{f i n}$ are the initial and final masses, respectively. And the transformation rate is:

$$
\frac{d \alpha}{d t}=-\frac{1}{m_{\text {in }}} \frac{d m}{d t}
$$

\section{Evaporation model: determination of the vapour pressure.}

\subsection{Evaporation model}

At the steady-state, the amount of vapour that reaches the crucible open end, Eq. (2), must be equal to the amount of vapour that is carried away by the purge gas, Eq. (4), i.e.:

$$
D S \frac{c_{s}-c_{h}}{h_{e f}}=v c_{h} S_{i}
$$

where $h$ in Eq. (2) has been substituted by an effective value. The evaporation rate is obtained substituting $c_{h}$ into Eq. (4):

$$
-\frac{d m}{d t}=\frac{D S c_{s}}{h_{e f}} \frac{h_{e f} v S_{i}}{D S+h_{e f} v S_{i}}
$$

Besides, $v$ is related to the volume flow rate of the purge gas, $Q$, according to 


$$
v=\eta \frac{Q}{S_{F}}
$$

where $S_{F}$ is the furnace cross section and $\eta$ is a dimensionless geometric factor that accounts for its actual value at the crucible position.

Combining Eqs. (13) and (14) we obtain:

$$
-\frac{d m}{d t}=\frac{D S c_{s}}{h_{e f}} \frac{h_{e f} \eta Q\left(S_{i} / S_{F}\right)}{D S+h_{e f} \eta Q\left(S_{i} / S_{F}\right)} .
$$

Beverley et al. [13] considered that the vapour was carried away by the purge gas through an area equal to the crucible cross-section (i.e. $S_{i}=S$ ). This is a very reasonable assumption because, in their experiments, the gas flowed parallel to the crucible axis. They also took $h_{e f}=h$ and $\eta=1$ and left the diffusion coefficient $D$ as the only free parameter to fit the mass-loss curves. The values of $D$ and $P_{s}$ obtained by Beverley et al. using Eq. (15) agreed very well with the literature.

Although the furnace used by Parker and Babas [14,15] was horizontal, they also took $S_{i}=S$ but considered $h_{e f}$ being different from $h$. In principle, their model contains two free parameters $\left(h_{e f}\right.$ and $\left.\eta\right)$, however, since they only considered data in the limit of diffusion-controlled evaporation $\left(h_{e f} \eta Q\left(S_{i} / S_{F}\right) \gg D S\right)$, the only fitting parameter is $h_{e f}$ :

$$
-\frac{d m}{d t}=\frac{D S c_{s}}{h_{e f}}
$$

The model used by Parker and Babas suffers from a conceptual problem; the volume of vapour carried away by the purge gas must be the product of the gas velocity times the area of a section normal to the velocity direction, whereas the open end of the crucible is tangent to it. This problem is highlighted in the opposite limit, when evaporation is controlled by the purge gas flow. When $h_{e f} \rightarrow 0$ their model reduces to:

$$
-\frac{d m}{d t}=\eta c_{S} Q\left(S / S_{F}\right)
$$

According to Eq. (17), the evaporation rate for a film should be proportional to the liquid surface area, $S$. However, our own results on TEA films (section 4.3) make clear that, on the contrary, no significant dependence on $S$ exists. So, it is necessary to adapt the model to the case of a horizontal furnace.

Indeed, the vapour is carried away in an area perpendicular to the gas flow direction, i.e., proportional to the furnace cross-section:

$$
S_{i}=\gamma S_{F}
$$


In the general case of arbitrary $h$, we get:

$$
-\frac{d m}{d t}=\frac{D S c_{s}}{h_{e f}} \frac{\phi h_{e f} Q}{D S+\phi h_{e f} Q} .
$$

where $\phi=\eta \gamma$ is a dimensionless geometric factor. As expected, in the limit of diffusioncontrolled evaporation, Eq. (19) reduces to Parker and Babas's result, Eq. (16). Moreover, in the opposite limit of a film, $h_{e f} \rightarrow 0$, the independence from $S$ is correctly predicted:

$$
-\frac{d m}{d t}=\phi c_{s} Q
$$

The cross-section for vapour carried away will be proportional to $S_{F}$, Eq. (19), provided that the vapour concentration will be almost constant between the liquid surface (or the open end of the crucible) and the furnace wall. This condition will be fulfilled if the diffusion time needed to reach the furnace wall,

$$
t_{D} \approx r^{2} / D
$$

( $r$ is the radius of the furnace tube), is shorter than the time interval needed for the purge gas to go along the sample length, $l$ :

$$
t_{v} \approx l / v
$$

Combination of Eqs. (21) and (22) together with Eq. (14) leads to the condition:

$$
Q<\pi l D
$$

Take the case of film on a $1 \mathrm{~cm}^{2}$ square substrate $\left(l=10^{-2} \mathrm{~m}\right)$ and a typical value of $D$ near room temperature of $2 \cdot 10^{-5} \mathrm{~m}^{2} / \mathrm{s}$. Eq. (22) delivers a maximum flow rate of 40 $\mathrm{cm}^{3} /$ min that is typical in most commercial equipment. For higher flow rates Eq. (19) is approximately valid but we cannot assume that $\phi$ is a constant; $\phi$ would depend on $Q$ and $D$. Finally, if evaporation takes place far from the triple point, one can assume that the vapour behaves as an ideal gas, thus, its concentration, $c_{S}$, is directly related to its partial pressure, Eq. (3). Hence, evaporation in a crucible can be expressed in terms of the vapour pressure,

$$
-\frac{d m}{d t}=\frac{D S M}{R T h_{e f}} \frac{\phi h_{e f} Q}{D S+\phi h_{e f} Q} P_{s} .
$$

And for a film,

$$
-\frac{d m}{d t}=\phi \frac{M}{R T} Q P_{S}
$$

\section{2 determination of the vapour pressure}

According to Eq. (25), $P_{S}$ can be directly evaluated from the mass loss rate data delivered by TG measurements on films, 


$$
P_{s}=-\frac{d m}{d t} \frac{R T}{\phi M Q}
$$

In order to determine the vapour pressure from Eq. (26), the only unknown parameter is the geometrical factor $\phi$. It can been determined using the Clausius-Clapeyron relationship [46,47],

$$
\frac{1}{P_{S}} \frac{d P_{S}}{d T}=-\frac{\Delta H_{v a p}}{R T}
$$

where $\Delta H_{\text {vap }}$ is the standard enthalpy of vaporization.

If $\Delta H_{v a p}$ is constant, then $P_{S}$ can be obtained after integration of Eq. (27),

$$
P_{S}=K \exp \left[-\frac{\Delta H_{v a p}}{R T}\right]
$$

Therefore, a plot of $\ln \left(-\frac{d m}{d t} \frac{R T}{M Q}\right)$ versus $1 / T$ should result in a straight line and the slope of this line should be $\Delta H_{v a p} / R$. Finally, $\phi$ is determined from the quotient between the results of the linear fit at the boiling point and the atmospheric pressure.

If the enthalpy of evaporation depends on the temperature, then according to Kirchhoff's law [48],

$$
\Delta H_{\text {vap }}(T)=\Delta H_{\text {vap }}\left(T_{\text {boil }}\right)+\int_{T}^{T_{\text {boil }}} \Delta C_{p} d T \approx \Delta H_{\text {vap }}\left(T_{\text {boil }}\right)+\Delta C_{p}\left(T_{\text {boil }}-T\right)
$$

where $\Delta C_{p}$ is the difference of the molar heat capacities of the liquid and vapour phase at constant pressure, and the approximate result is valid for experiments conducted over narrow temperature ranges. The dependence of $P_{S}$ on $T$ is obtained from the integration of Eq. (27) with $\Delta H_{\text {vap }}$ given by (29),

$$
\ln P_{S}=\frac{\Delta H_{\text {vap }}\left(T_{\text {boil }}\right)}{R T}+\frac{\Delta C_{p}}{R} \ln (T)+K
$$

The values of $\Delta C_{p}$ and $\Delta H_{v a p}\left(T_{b o i l}\right)$ can be determined from a nonlinear fit of $\ln \left(-\frac{d m}{d t} \frac{R T}{M Q}\right)$ to the temperature dependence of Eq. (30). Finally, $\phi$ is determined the quotient between the result of the nonlinear fit at the boiling point and the atmospheric pressure.

\section{Results and discussion}

\subsection{Water evaporation: determination of the vapour pressure.}

In Figure 2, we have plotted the evolution of water evaporation for $20 \mathrm{mg}$ mass films deposited over a $100 \mathrm{~mm}^{2}$ area LAO substrate. Experiments have been performed at 
four different heating rates and for a purge gas flow $Q=40 \mathrm{~cm}^{3} / \mathrm{min}$. From the slope of such a plot in the temperature range between 27 and $60^{\circ} \mathrm{C}$ we obtain $\Delta H_{v a p}=42.0 \pm 0.1$ $\mathrm{kJ} / \mathrm{mol}$ that is in good agreement with the values of literature; TG measurements around $60^{\circ} \mathrm{C}$ deliver a value of $43.8 \mathrm{~kJ} / \mathrm{mol}$ [22] and according to [49] at 25 and $60^{\circ} \mathrm{C} \Delta H_{\text {vap }}$ is 43.8 and $42.3 \mathrm{~kJ} / \mathrm{mol}$ respectively. Finally, from Eqs. (26) and (27) we obtain $\phi=0.484$ $\left(T_{\text {boil }}=373.17 \mathrm{~K}\right.$ and $M$ is $\left.18.0153 \mathrm{~g} / \mathrm{mol}\right)$.

In Figure 3 we have plotted the well-established values of $P_{S}$ [50] (stars) together with the values of $P_{S}$ obtained from TG data (symbols), Eq. (26); there is a nice agreement between the $P_{S}$ values of the bibliography and those obtained using our method. In addition, we have plotted the $P_{S}$ values calculated from our linear fit, Eq. (28). It is also worth noting the good alignment of the data.

With the temperature evolution of $P_{S}$ determined above, we have simulated the evaporation of water for two different geometries: films deposited on a substrate, Eq. (25), and water inside an open crucible, Eq (24). In the case of water inside a crucible $h$ has been determined from the difference between the crucible volume and the volume occupied by the remaining liquid, the value of the diffusivity has been determined from the literature (see appendix A) and $S$ is $38.5 \mathrm{~mm}^{2}$. As for parameter $\phi$ we assume the same value for films and crucibles, $\phi=0.484$. From Figure 2 it is apparent that our model is able to reproduce the actual kinetics, even in the case of a crucible where both diffusion and purge gas flow contribute to limit the evaporation rate (the numerical results show that the contribution of both terms is similar).

Despite the good linear fit and the correctness of our $P_{S}$ values, the fitted value of $\Delta H_{\text {vap }}$ slightly deviates from the reported value at the boiling point, $\Delta H_{\text {vap }}\left(T_{\text {boil }}\right)=40.657 \mathrm{~kJ} / \mathrm{mol}$ [49]. The reason, as pointed out by Vyazovkin et al. [21,22], is the fact that the enthalpy of evaporation depends on the temperature. For water, $P_{S}$ can be calculated from Eq. (30) with $\Delta C_{p}=42 \mathrm{~J} / \mathrm{Kmol}$ (the molar heat capacities of liquid and water vapour are 75.29 and $33.58 \mathrm{~J} / \mathrm{mol} \mathrm{K}$, respectively). Constant $K$ in Eq. (30) can be determined taking into account that, at $T_{b o i l}, P_{S}=1 \mathrm{~atm}$. In Figure 3, the dashed line corresponds to the value of $P_{S}$ determined from Eq. (30). The agreement between the reported values of $P_{S}$ with those calculated from Eq. (30) is excellent. It is also clear that, for the lowest temperature, the deviations of $P_{S}$ from linearity are related to the dependence of the $\Delta H_{\text {vap }}$ on $T$.

Since in the temperature range going from our experimental data up to the boiling point the dependence of $\ln \left(P_{S}\right)$ on $1 / T$ is nearly linear, we have been able to 
obtain an accurate determination of $P_{S}$. However, this is not the general case as it will be shown with TEA evaporation.

\subsection{TEA evaporation: qualitative analysis.}

In this section, we want to analyse if the TEA mass-loss is due to evaporation or thermal decomposition.

Figure 4 shows the TGA curves obtained when TEA was heated at $10 \mathrm{~K} / \mathrm{min}$ under a flow rate of $40 \mathrm{~cm}^{3} / \mathrm{min}$ of $\mathrm{N}_{2}$, Ar or $\mathrm{O}_{2}$ for different sample masses and arrangements. It is apparent that kinetics depends on the initial sample mass; the smaller the mass, the faster the evolution. Also the simple shape of the curves suggest that the kinetics is governed by a single step process, only the experiment performed with a crucible and a pinned lid shows a complex evolution that arises from several concurrent mechanisms.

All the evolutions with films and with the open crucible end abruptly with a discontinuity, i.e., the transformation rate goes abruptly to zero at the end of the process. This behaviour is characteristic of a zeroth order transformation. Additionally, the process shifts to higher temperatures when the gas exchange between the sample and the furnace atmosphere is further impeded; the fastest kinetics is obtained with films while the slowest kinetics is observed in the case of the crucible with a lid. Indeed, it has been noticed that the kinetics of evaporation depends on the sample mass and the method of sample loading [23].

The kinetics will be governed by evaporation provided that there is neither chemical reaction between TEA and the surrounding gas nor TEA pyrolysis. As we will see in section 4.5 the decomposition of TEA is enhanced in the presence of $\mathrm{O}_{2}$. From Figure 4 it is apparent that in the case of films, the kinetics is not affected by the presence of $\mathrm{O}_{2}$ (for an initial mass of $20 \mathrm{mg}$, the evolutions under $\mathrm{N}_{2}$ and under $\mathrm{O}_{2}$ overlap). Conversely, for TEA inside an open crucible and an initial mass of $77 \mathrm{mg}$, the evolution obtained under $\mathrm{O}_{2}$ is shifted to lower temperatures when compared to the evolution under $\mathrm{N}_{2}$. Thus, apparently, no TEA decomposition occurs in films, while in crucibles the decomposition of TEA is not negligible, at least, in the presence of $\mathrm{O}_{2}$. This conclusion will be verified with the analysis of evolved gases in section 4.5.

Eqs. (11), (24) and (25) predict that $d \alpha / d t$ is inversely proportional to the initial mass, $m_{i n}$. This particular dependence on $m_{i n}$ is in contradiction with a kinetics governed by thermal decomposition. In this case, the kinetics should be independent of the initial 
sample mass. Furthermore, according to Eq. (7) the transformation rate is also inversely proportional to the heating rate. Thus, for film evaporation doubling the sample mass has the same effect than doubling the heating rate. This prediction is confirmed by the experimental results plotted in Figure 5 ; the $20 \mathrm{~K} / \mathrm{min}-20 \mathrm{mg}$ evolution coincides with that measured at $10 \mathrm{~K} / \mathrm{min}$ on a mass of $40 \mathrm{mg}$. Similar agreement is seen between the 5 $\mathrm{K} / \mathrm{min}-20 \mathrm{mg}$ and $10 \mathrm{~K} / \mathrm{min}-10 \mathrm{mg}$ and between the $2.5 \mathrm{~K} / \mathrm{min}-20 \mathrm{mg}$ and $5 \mathrm{~K} / \mathrm{min}-10$ mg experiments.

Also, Eq. (25) predicts that the evaporation rate does not depend on the film surface. In Figure 5, we have plotted the observed evaporation for two $5 \mathrm{mg}$ films deposited on $10 \times 10 \mathrm{~mm}^{2}$ and $5 \times 5 \mathrm{~mm}^{2}$ substrates. Again, the prediction is fulfilled, since the results nearly overlap despite the factor of 4 between both surface areas. This particular result is especially significant because our model differs from that of Parker and Babas [15] on the dependence of the evaporation rate on surface area.

Finally, contrarily to what one would expect for a decomposition process, the evaporation model of Eq. (25) does not contain any explicit dependence of the evaporation rate on $\alpha$. Thus, evaporation follows a zeroth order kinetics, and its rate should go abruptly to zero when the liquid is exhausted, as observed.

\subsection{The equilibrium vapour pressure of TEA.}

The set of experiments performed to determine the TEA vapour pressure is shown in Figure 5.

In Appendix B the temperature dependence of TEA vapour pressure values retrieved from the literature is analysed. The $\ln \left(P_{S}\right)$ versus $1 / T$ plot of Figure B1 reveals that the simple linear fit described in section 3.1 cannot be used here. With the help of the nonlinear fitting tool of Origin software we have fitted our experimental values to Eq. (30). The relevant aspects that should be taken into account to obtain a correct fit are described in Appendix C. From the nonlinear fit we have obtained $\Delta H_{v a p}\left(T_{b o i l}\right)=79$ $\pm 2 \mathrm{~kJ} / \mathrm{mol}$ and $\Delta C_{p}=58 \pm 2 \mathrm{~J} /(\mathrm{Kmol})$. These values are in fair agreement with the data retrieved from the literature (Appendix B: $\Delta H_{\text {vap }}\left(T_{b o i l}\right)=76 \pm 2 \mathrm{~kJ} / \mathrm{mol}$ and $\Delta C_{p}=68 \pm 2$ $\mathrm{J} /(\mathrm{Kmol}))$.

From Eqs. (24) and (30) we obtain $\phi=1.07$ (for TEA $T_{\text {boil }}=608.55 \mathrm{~K}$ and $M=$ 149.1882). Once we know $\phi$ the values of $P_{S}$ can be directly determined from the TG measurements by means of Eq. (26). From Figure 7 it is clear that there is a nice 
agreement between the $P_{S}$ values obtained with our method (symbols in Figure 7) and those found in the literature (dashed line in Figure 7). It is also worth noting that our method allows determining $P_{S}$ in a pressure range larger than four decades.

Finally, from Eq. (26) we can simulate the evolution of the evaporated fraction at different heating rates. The result of the simulation (solid lines in Figure 5) agrees very well with the experiment.

The differences between the values of $\Delta H_{\text {vap }}$ and $\Delta C_{p}$ determined from the nonlinear fit and those of the literature are clearly beyond the tolerances. If we perform the Taylor series expansion of Eq. (30) as a function of $T_{b o i l} / T$, we obtain,

$$
\ln P_{S}=K+\frac{\Delta C_{p}}{R}\left[\ln \left(T_{\text {boil }}\right)+1\right]+\left[\frac{\Delta H_{\text {vap }}\left(T_{\text {boil }}\right)}{R T_{\text {boil }}}-\frac{\Delta C_{p}}{R}\right] \frac{T_{\text {boil }}}{T}+\frac{1}{2} \frac{\Delta C_{p}}{R}\left(\frac{T_{\text {boil }}}{T}-1\right)^{2}+\cdots(
$$

Note, that $\Delta H_{v a p}$ and $\Delta C_{p}$ are coupled in the first order term and that we need to go to the second order term to determine the value of $\Delta C_{p}$ independently from the value of $\Delta H_{v a p}$. Thus, we will be able to retrieve confidently accurate values of $\Delta H_{v a p}$ and $\Delta C_{p}$ when $\ln P_{S}$ clearly departs from linearity. From figure 7 it is apparent that the deviations from linearity are quite small, and this is generally the case, i.e., despite that our method allows to accurately determine the value of $P_{S}$, it cannot be used to determine $\Delta H_{v a p}$ and $\Delta C_{p}$. Conversely, if $\Delta C_{p}$ is known, the $\Delta H_{v a p}$ can be accurately determined. We have repited the nonlinear fit but fixing and $\Delta C_{p}=68 \pm 2 \mathrm{~J} /(\mathrm{Kmol})$. Under this constraint we obtain $\Delta H_{\text {vap }}\left(T_{\text {boil }}\right)=77.6 \pm 0.1 \mathrm{~kJ} / \mathrm{mol}$ which is in agreement with the value delivered by the literature.

\subsection{Applicability of isoconversional and Kissinger methods}

Application of the Kissinger equation or isoconversional kinetic methods to evaporation must be done with caution. The reason is that most kinetics methods assume that the transformation rate, Eqs. (5) or (8), depends exclusively on the temperature and the degree of transformation whereas the evaporation rate depends on the sample mass, purge gas flow and sample free surface or crucible dimensions. Therefore, to perform an isoconversional analysis it is compulsory to fix the experimental conditions and, in particular, to keep constant the initial sample mass, the gas flow rate and free surface or crucible dimensions.

In addition, most kinetic methods assume an Arrhenius temperature dependence for the rate constant, Eqs. (5) or (8). In the case of evaporation, Eqs. (24) and (25), the 
temperature dependence is dominated by the exponential dependence of $P_{S}$, Eq. (27). Therefore, the expected activation energy should be $\Delta H_{v a p}$. Since $\Delta H_{v a p}$ depends on the temperature, Eq. (29), the kinetic methods would deliver a sort of an average value of $\Delta H_{\text {vap }}$ in the temperature interval explored. The Kissinger plot and the activation energy obtained from Friedman and advanced isoconversional methods are shown in Figure 8., To reduce the inaccuracies related to the determination of the transformation rate, in the Friedman analysis data has been smoothed using a Savitzky-Golay filter. In both cases, the activation energy is determined from the six experiments performed in films under identical conditions but different heating rates, Figure 6. Friedman and advanced isoconversional analysis delivers a nearly constant activation energy of $85 \mathrm{~kJ} / \mathrm{mol}$ (in the $\alpha$ range from 0.1 to $0.8, E_{\alpha}$ varies between 83.7 and $85.9 \mathrm{~kJ} / \mathrm{mol}$ ) that is in agreement with the value of $84 \mathrm{~kJ} / \mathrm{mol}$ obtained from the slope of the Kissinger plot and within the expected $\Delta H_{v a p}$ interval (the temperature range explored goes from 360 to $516 \mathrm{~K}$ thus $\Delta H_{\text {vap }}$ varies from 92.6 to $82.0 \mathrm{~kJ} / \mathrm{mol}$ ).

The constancy of the activation energy delivered by Friedman method confirms that the process is mainly described by a single mechanism. The deviations of $E_{A}$ at the beginning and final stages are related to the experimental issues described Appendix C. Since evaporation is a zeroth order process, the maximum transformation rate is achieved just at the end of the process. Thus, Kissinger analysis relies in the evolution at the end of the process. However, at the final stages the actual process deviates from the evaporation model, consequently Kissinger would be significantly less accurate than isoconversional methods. This fact explains why there is not a nice alignment in the Kissinger plot.

\subsection{TEA decomposition.}

Two factors control de degradation rate of TEA; the atmosphere and temperature. In particular, the degradation is enhanced by the presence of oxygen and when evaporation is impeded so TEA is heated at higher temperatures.

In Figure 9 we have plotted the IR spectrum of the volatiles evolved when a film of mass $22 \mathrm{mg}$ is heated at $10 \mathrm{~K} / \mathrm{min}$ under a wet $\mathrm{O}_{2}$ flow. In particular we have chosen the gases evolved at $230^{\circ} \mathrm{C}$ that corresponds to the peak temperature (the temperature at which the transformation rate is higher). In Figure 9 we have also plotted the spectra of the identified volatiles: acetaldehyde, TEA and $\mathrm{CO}_{2}$. In addition to these volatiles, the 
presence of water is also apparent from the noisy-like absorption bands between 3500 and $4000 \mathrm{~cm}^{-1}$ and between 1200 and $2000 \mathrm{~cm}^{-1}$. The main volatile is TEA; its presence is revealed by the strong absorption peaks located at 1040, 1074, 2822, 2885 and 2955 $\mathrm{cm}^{-1}$ (see Table 1). It is worth noting that despite the fact that the ATR cell and the connection tube are heated at $200^{\circ} \mathrm{C}$, we have observed that a significant amount of TEA condenses in its way between the TG furnace and the ATR cell, thus only a fraction of the evolved TEA is detected. Apart from TEA, we detect $\mathrm{CO}_{2}$ and traces of acetaldehyde (shoulder at $2700 \mathrm{~cm}^{-1}$ ). Besides, in the case of $20 \mathrm{mg}$ films under a flow of $\mathrm{N}_{2}$, no acetaldehyde is observed.

According to Schwarz [51] TEA decomposes to form acetaldehyde and diethanolamine (DEA) through protonation with a hydrogen atom from another TEA molecule:

$$
\mathrm{N}\left(\mathrm{CH}_{2} \mathrm{CH}_{2} \mathrm{OH}\right)_{3} \rightarrow \mathrm{CH}_{3} \mathrm{CHO}+\mathrm{HN}\left(\mathrm{CH}_{2} \mathrm{CH}_{2} \mathrm{OH}\right)_{2}
$$

When open crucibles are used instead of films, the formation of acetaldehyde is more evident, Figs. 10 and 11. As we have seen in the previous section, the use of crucibles and larger sample masses delays TEA evaporation, so most of TEA evaporation occurs at higher temperatures and therefore the amount of TEA that decomposes increases. In particular, in Figure 10 we show the volatiles formed at the peak temperature when a mass of $175 \mathrm{mg}$ of TEA is placed inside an open crucible and under a flow of argon. In this case we observe the presence of TEA, but the peaks related to the spectrum of acetaldehyde are more prominent, in particular the absorptions at 1128, 2697 and 2729 $\mathrm{cm}^{-1}$. Also ethylene oxide has been identified; in particular we have observed the sharp absorptions at 3007 and $3070 \mathrm{~cm}^{-1}$ and the broad bands centred at 864 and $3097 \mathrm{~cm}^{-1}$. Acetaldehyde may be formed from the protonation of TEA to give DEA but DEA protonation may also result in the formation of acetaldehyde and monoethanolamine (MEA). Besides, thermal decomposition of MEA involves the formation of ammonia and ethylene oxide,

$$
\mathrm{NH}_{2} \mathrm{CH}_{2} \mathrm{CH}_{2} \mathrm{OH} \rightarrow \mathrm{NH}_{3}+\mathrm{CH}_{2} \mathrm{OCH}_{2} \text {. }
$$

However, one cannot rule out that the formation of ethylene oxide may come directly from the decomposition of TEA or DEA. We have not detected DEA or MEA so we cannot assure that they are intermediates during TEA decomposition, but it must be stressed that their spectra overlaps with that of TEA and that they are less stable than TEA, so once formed they will easily decompose, thus it may be not possible to ascertain their presence by IR. 
Finally, the decomposition of TEA in the vapour phase is significantly enhanced in the presence of oxygen. In Figure 11 we show the IR spectrum obtained when TEA inside a crucible is heated at $10 \mathrm{~K} / \mathrm{min}$ under a flow of oxygen. In particular, Figure 11 is a snapshot taken at $296^{\circ} \mathrm{C}$. In this case, no TEA is detected so TEA decomposition is nearly complete. Thanks to the absence of TEA, the presence of acetaldehyde and ethylene oxide is more evident. We also observe $\mathrm{CO}, \mathrm{H}_{2} \mathrm{O}$ and a larger amount of $\mathrm{CO}_{2}$ that can be attributed to the oxidation of organic molecules.

\section{Conclusions}

We have developed a model that describes the evaporation kinetics in films and crucibles that takes into account vapour diffusion and vapour carried away by the purge gas flow. The model is valid for horizontal furnaces where the purge gas flows parallel to the liquid film and perpendicular to the crucible axis.

The evaporation rate is proportional to the equilibrium vapour pressure. Consequently the rate constant follows an Arrhenius temperature dependence. We have shown that this model successfully describes TEA and water evaporation.

The use of films to analyse the evaporation kinetics has several avantages: a) the determination of the vapour pressure from TG is straightforward, b) liquid cooling related to its evaporation is negligible and, c) allows exploring lower temperatures and a wider temperature interval than with crucibles.

We have developed a method to determine the equilibrium vapour pressure based on the TG analysis of films performed at different heating rates. The method has been successfully applied to water and TEA evaporation. In the case of TEA we have been able to determine the equilibrium vapour pressure in a pressure range four decades wide.

We have shown that, to determine the kinetics by means of an isoconversional method, it is compulsory to keep constant the initial sample mass, the gas flow and the sample surface area.

Finally, we have observed TEA degradation only occurs with crucibles and not in films, and that degradation increases with temperature and in the presence of oxygen. The main volatiles formed are acetaldehyde and ethylene oxide.

\section{Appendix A. Water vapour diffusivity in $\mathbf{N}_{2}$.}


The mass diffusivity of the vapour (A) through the surrounding gas (B), is given by $[52,53]$,

$$
D_{A B}=\frac{1.8826210^{-22} T^{3 / 2}}{P \sigma_{A B}^{2} \Omega_{D}}\left[\frac{1}{M_{A}}+\frac{1}{M_{B}}\right]^{1 / 2},
$$

where $D_{A B}$ is in $\mathrm{m}^{2} / \mathrm{s}, \Omega_{\mathrm{D}}$ is the "collision integral", $P$ is the absolute pressure in $\mathrm{Pa}, M$ is the molecular mass of the gas in $\mathrm{g} / \mathrm{mol}$ and $\sigma$ is the "collision diameter" in $\mathrm{m} . \Omega_{\mathrm{D}}$ is a function of the temperature and the energy of molecular interactions, $\varepsilon_{\mathrm{i}}$. The values of $\Omega_{D}$ are tabulated in ref. [52]. Besides, for a binary system of nonpolar molecular pairs, the collision diameter and the energy of molecular interaction are:

$$
\sigma_{A B}=\frac{\sigma_{A}+\sigma_{B}}{2} \text { and } \varepsilon_{A B}=\sqrt{\varepsilon_{A} \varepsilon_{B}} \text {. }
$$

For water, the values of $\sigma$ and $\varepsilon$ are tabulated in ref. [52], in particular $\sigma_{\mathrm{H}_{2} \mathrm{O}}=$ $2.64910^{-10} \mathrm{~m}, \sigma_{N_{2}}=3.61710^{-10} \mathrm{~m}, \varepsilon_{H_{2} O}=4.91510^{-21} \mathrm{~J}$ and $\varepsilon_{N_{2}}=1.3410^{-21} \mathrm{~J}$. The dependence $D_{\mathrm{H}_{2} \mathrm{O}, \mathrm{N}_{2}}$ on the temperature between 273 and $373 \mathrm{~K}$ is plotted in Figure A1. $D_{H_{2} O, N_{2}}$ has been fitted to a power dependence on the temperature,

$$
D_{\mathrm{H}_{2} \mathrm{O}, \mathrm{N}_{2}}=D_{\mathrm{H}_{2} \mathrm{O}, \mathrm{N}_{2}}^{300 \mathrm{~K}}\left(\frac{T}{300}\right)^{n}
$$

where $D_{\mathrm{H}_{2} \mathrm{O}, \mathrm{N}_{2}}^{30 \mathrm{~K}}=2.5310^{-5} \mathrm{~m}^{2} / \mathrm{s}$ and $n=1.86$.

\section{Appendix B. Vapour pressure of TEA from a literature review}

Several authors have measured the vapour pressure of TEA at different temperature ranges: 523.59-578.75 K [54], 523-579 [55], 433.15-513.15 [56] and at 329.35 [57]. In addition, the enthalpy of evaporation of TEA has also been determined at different temperatures: 433.15-513.15 [56], 329.35-340.26 [57], 538 [55] and at $533 \mathrm{~K}$ [12]. These results are summarized in Figure B1.

In relatively narrow temperature ranges the difference between the molar heat capacities of a liquid and its vapour is constant. Thus, according Kirchhoff's law, Eq. (29), there is a linear dependence between the enthalpy of evaporation and the temperature, such linearity is apparent in Figure B1. From the linear fit, shown in Figure B1, we have determined the enthalpy of evaporation at the boiling point, $608.55 \mathrm{~K}$, and the molar heat capacity difference: $\Delta H_{\text {vap }}\left(T_{\text {boil }}\right)=76 \pm 2 \mathrm{~kJ} / \mathrm{mol}$ and $\Delta C_{p}=68 \pm 2$ 
$\mathrm{J} /(\mathrm{Kmol})$, respectively (the uncertainties correspond to the standard error of the linear fit).

Once we know the dependence of $\Delta H_{v a p}$ on $T$, we can calculate $P_{S}$ as a function of temperature by using Eq. (30) (the integration constant is determined after imposing that, at the boiling point, $\left.P_{S}=1 \mathrm{~atm}\right)$. The result is show in Figure B1. The agreement between the literature values of $P_{S}$ and Eq. (30) confirms that $P_{S}$ can be accurately determined using this equation and gives us good confidence on the values reported.

\section{Appendix C. Non-linear fit procedure.}

To confidently determine $P_{S}$ from the non-linear fit of the TG data to Eq. (30), several issues should be taken into account. First, since the determination of $P_{S}$ is based on the extrapolation of the non-linear fit up to the boiling point, it is important to cover a temperature range as large as possible to obtain a reliable temperature dependence. Also it is important to perform measurements at relatively high heating rates $(40 \mathrm{~K} / \mathrm{min}$ or superior) to obtain data at relatively high temperatures, the nearer the data to the boiling point is, the more accurate the analysis is. Whenever these conditions cannot be fulfilled, it will be necessary to determine at least one value of $P_{S}$ within the explored temperature range.

Most commercial TG apparatuses record the mass at a constant sampling time interval. Since experiments performed at low heating rates are much longer in time, the amount of data of these experiments is significantly larger than those performed at high heating rates. As a consequence, the data obtained at low temperature is significantly overrated; this fact has a detrimental effect on the reliability of the nonlinear fit and in particular on the extrapolation at the boiling point. To minimize this effect, it is crucial to introduce a statistical weight in the computation of the nonlinear fit. In our case, for a particular experiment, its statistical weigh is the number of points of the longest experiment divided by its number of points.

Finally, the data related to the first and last stages of evaporation significantly deviates from linearity and had to be discarded. The reason is that, at the first stages, the transformation rate is very small; it is very sensitive to noise and baseline artefacts. Conversely, at the last stages, the film collapses into droplets and the model fails to

provide an accurate description. In Figure $C 1$ we show the plot of $\ln \left(-\frac{d m}{d t} \frac{R T}{M Q}\right)$ versus 
$1 / T$ for all the data of the experiments shown in Figure 6. From this graph it is apparent that the first and last points of each experiment clearly deviate from the general alignment. These points have to be removed to obtain a correct fitting. 


\section{Acknowledgements}

This work was partially funded by the Spanish Programa Nacional de Materiales through project MAT2014-51778-C2-2-R, by the Generalitat de Catalunya contract No. 2014SGR-00948 and by the Universitat de Girona contract No. MPCUdG2016/059. 


\section{References}

[1] I. Langmuir, The Vapor Pressure of Metallic Tungsten, Phys. Rev. 2 (1913) 329342. doi:10.1103/PhysRev.2.329.

[2] M. Knudsen, The kinetic theory of gases: some modern aspects, Methuen \& Co, London, United Kingdom, 1950.

[3] I.W. Eames, N.J. Marr, H. Sabir, The evaporation coefficient of water: a review, Int. J. Heat Mass Transf. 40 (1997) 2963-2973. doi:10.1016/S00179310(96)00339-0.

[4] A. Hazra, D. Dollimore, K. Alexander, Thermal analysis of the evaporation of compounds used in aromatherapy using thermogravimetry, Thermochim. Acta. 392-393 (2002) 221-229. doi:10.1016/S0040-6031(02)00104-1.

[5] K. Chatterjee, D. Dollimore, K. Alexander, A new application for the Antoine equation in formulation development, Int. J. Pharm. 213 (2001) 31-44.

doi:10.1016/S0378-5173(00)00644-X.

[6] D.M. Price, M. Hawkins, Calorimetry of two disperse dyes using thermogravimetry, Thermochim. Acta. 315 (1998) 19-24. doi:10.1016/S00406031(98)00272-X.

[7] S.J. Ashcroft, The measurement of enthalpies of sublimation by thermogravimetry, Thermochim. Acta. 2 (1971) 512-514. doi:10.1016/00406031(71)80021-7.

[8] S. Materazzi, S. Vecchio, Recent Applications of Evolved Gas Analysis by Infrared Spectroscopy (IR-EGA), Appl. Spectrosc. Rev. 48 (2013) 654-689. doi:10.1080/05704928.2013.786722.

[9] S. Vecchio, Thermogravimetric method for a rapid estimation of vapor pressure and vaporization enthalpies of disubstituted benzoic acids: an attempt to correlate vapor pressures and vaporization enthalpies with structure, Struct. Chem. 24 (2013) 1821-1827. doi:10.1007/s11224-013-0232-2.

[10] D.M. Price, A fit of the vapours, Thermochim. Acta. 622 (2015) 44-50. doi:10.1016/j.tca.2015.04.030.

[11] P. Phang, D. Dollimore, S.J. Evans, A comparative method for developing vapor pressure curves based on evaporation data obtained from a simultaneous TGDTA unit, Thermochim. Acta. 392-393 (2002) 119-125. doi:10.1016/S00406031(02)00092-8.

[12] S.F. Wright, D. Dollimore, J.G. Dunn, K. Alexander, Determination of the vapor 
pressure curves of adipic acid and triethanolamine using thermogravimetric analysis, Thermochim. Acta. 421 (2004) 25-30. doi:10.1016/j.tca.2004.02.021.

[13] K.J. Beverley, J.H. Clint, P.D.I. Fletcher, Evaporation rates of pure liquids measured using a gravimetric technique, Phys. Chem. Chem. Phys. 1 (1999) 149-153. doi:10.1039/a805344h.

[14] Y. Rong, C.M. Gregson, A. Parker, Thermogravimetric measurements of liquid vapor pressure, J. Chem. Thermodyn. 51 (2012) 25-30. doi:10.1016/j.jct.2012.02.021.

[15] A. Parker, R. Babas, Thermogravimetric measurement of evaporation: Data analysis based on the Stefan tube, Thermochim. Acta. 595 (2014) 67-73. doi:10.1016/j.tca.2014.09.011.

[16] N. Pieterse, W.W. Focke, Diffusion-controlled evaporation through a stagnant gas: Estimating low vapour pressures from thermogravimetric data, Thermochim. Acta. 406 (2003) 191-198. doi:10.1016/S0040-6031(03)00256-9.

[17] M. Tesconi, S.H. Yalkowsky, A novel thermogravimetric method for estimating the saturated vapor pressure of low volatility compounds, J. Pharm. Sci. 87 (1998) 1512-1520. doi:10.1021/js980231s.

[18] F. Barontini, V. Cozzani, Assessment of systematic errors in measurement of vapor pressures by thermogravimetric analysis, Thermochim. Acta. 460 (2007) 15-21. doi:10.1016/j.tca.2007.05.005.

[19] J. Farjas, D. Sánchez-Rodríguez, H. Eloussifi, P. Roura, Thermal Gradients in Thermal Analysis Experiments, in: J. Šesták, P. Hubík, J.J. Mareš (Eds.), Therm. Phys. Therm. Anal. From Macro to Micro, Highlighting Thermodyn. Kinet. Nanomater., Budapest, 2017: pp. 345-362. doi:10.1007/978-3-319-45899-1_16.

[20] D. Sánchez-Rodríguez, H. Eloussifi, J. Farjas, P. Roura, M. Dammak, Thermal gradients in thermal analysis experiments: Criterions to prevent inaccuracies when determining sample temperature and kinetic parameters, Thermochim. Acta. 589 (2014) 37-46. doi:10.1016/j.tca.2014.05.001.

[21] S. Vyazovkin, Isoconversional Kinetics of Thermally Stimulated Processes, Springer International Publishing, Heidelberg, 2015. doi:10.1007/978-3-31914175-6.

[22] J.R. Prado, S. Vyazovkin, Activation energies of water vaporization from the bulk and from laponite, montmorillonite, and chitosan powders, Thermochim. Acta. (2011). doi:10.1016/j.tca.2011.06.005. 
[23] M. Suşeska, M. Rajiş, S. Matečiş-Mušan, S. Zeman, Z. Jalový, Kinetics and heats of sublimation and evaporation of 1,3,3-trinitroazetidine (TNAZ), J. Therm.

Anal. Calorim. 74 (2003) 853-866. doi:10.1023/B:JTAN.0000011017.65451.96.

[24] N. Sbirrazzuoli, S. Vecchio, A. Catalani, Isoconversional kinetic study of alachlor and metolachlor vaporization by thermal analysis, Int. J. Chem. Kinet. 37 (2005) 74-80. doi:10.1002/kin.20054.

[25] Y. Cheng, Y. Huang, K. Alexander, D. Dollimore, A thermal analysis study of methyl salicylate, Thermochim. Acta. 367-368 (2001) 23-28.

doi:10.1016/S0040-6031(00)00689-4.

[26] A. Sayari, Y. Belmabkhout, R. Serna-Guerrero, Flue gas treatment via CO2 adsorption, Chem. Eng. J. 171 (2011) 760-774. doi:10.1016/j.cej.2011.02.007.

[27] W. Wattanathana, N. Nootsuwan, C. Veranitisagul, N. Koonsaeng, N. Laosiripojana, A. Laobuthee, Simple cerium-triethanolamine complex: Synthesis, characterization, thermal decomposition and its application to prepare ceria support for platinum catalysts used in methane steam reforming, J. Mol. Struct. 1089 (2015) 9-15. doi:10.1016/j.molstruc.2015.02.010.

[28] I. Mylonas-Margaritis, J. Mayans, S.-M. Sakellakou, C. P. Raptopoulou, V. Psycharis, A. Escuer, S. P. Perlepes, Using the Singly Deprotonated Triethanolamine to Prepare Dinuclear Lanthanide(III) Complexes: Synthesis, Structural Characterization and Magnetic Studies, Magnetochemistry. 3 (2017) 5. doi:10.3390/magnetochemistry3010005.

[29] D. Sánchez-Rodríguez, S. Yamaguchi, D. Ihara, H. Yamaura, H. Yahiro, Selfpropagating high-temperature synthesis of highly dispersed noble metals on ceria powder: Application to $\mathrm{Pd} / \mathrm{CeO} 2$ catalyst, Ceram. Int. 43 (2017) 14533-14536. doi:10.1016/j.ceramint.2017.07.208.

[30] R.K. Pati, I.C. Lee, K.J. Gaskell, S.H. Ehrman, Precipitation of Nanocrystalline CeO 2 Using Triethanolamine, Langmuir. 25 (2009) 67-70. doi:10.1021/la8031286.

[31] T. Schneller, R. Waser, M. Kosec, D. Payne, eds., Chemical Solution Deposition of Functional Oxide Thin Films, Springer Vienna, Vienna, 2013. doi:10.1007/978-3-211-99311-8.

[32] B. Schoofs, T. Mouganie, B.A. Glowacki, V. Cloet, S. Hoste, I. Van Driessche, Synthesis of highly textured superconducting NdBa2Cu3O7-y thin films by two aqueous sol-gel dip coating techniques, J. Sol-Gel Sci. Technol. 41 (2007) 113- 
122. doi:10.1007/s10971-006-0517-7.

[33] X. Palmer, C. Pop, H. Eloussifi, B. Villarejo, P. Roura, J. Farjas, A. Calleja, A. Palau, X. Obradors, T. Puig, S. Ricart, Solution design for low-fluorine trifluoroacetate route to YBa 2 Cu 3 O 7 films, Supercond. Sci. Technol. 29 (2016) 024002. doi:10.1088/0953-2048/29/2/024002.

[34] P. Vermeir, I. Cardinael, J. Schaubroeck, K. Verbeken, M. Bäcker, P. Lommens, W. Knaepen, J. D'haen, K. De Buysser, I. Van Driessche, Elucidation of the mechanism in fluorine-free prepared $\mathrm{YBa} 2 \mathrm{Cu} 3 \mathrm{O}$ (7-delta) coatings., Inorg. Chem. 49 (2010) 4471-7. doi:10.1021/ic9021799.

[35] X. Obradors, T. Puig, S. Ricart, M. Coll, J. Gazquez, A. Palau, X. Granados, Growth, nanostructure and vortex pinning in superconducting $\mathrm{YBa} 2 \mathrm{Cu} 3 \mathrm{O} 7$ thin films based on trifluoroacetate solutions, Supercond. Sci. Technol. 25 (2012) 123001. doi:10.1088/0953-2048/25/12/123001.

[36] J. Farjas, P. Roura, Exact analytical solution for the Kissinger equation: Determination of the peak temperature and general properties of thermally activated transformations, Thermochim. Acta. 598 (2014) 51-58. doi:10.1016/j.tca.2014.10.024.

[37] J. Farjas, P. Roura, Isoconversional analysis of solid state transformations. A critical review. Part I. Single step transformations with constant activation energy, J. Therm. Anal. Calorim. 105 (2011) 757-766. doi:10.1007/s10973-011$1446-4$.

[38] J. Farjas, P. Roura, Isoconversional analysis of solid state transformations. A critical review. Part II. Complex transformations, J. Therm. Anal. Calorim. 105 (2011) 767-773. doi:10.1007/s10973-011-1447-3.

[39] H.L. Friedman, Kinetics of thermal degradation of char-forming plastics from thermogravimetry. Application to a phenolic plastic, J. Polym. Sci. Part C Polym. Symp. 6 (1964) 183-195. doi:10.1002/polc.5070060121.

[40] S. Vyazovkin, Modification of the integral isoconversional method to account for variation in the activation energy, J. Comput. Chem. 22 (2001) 178-183. doi:10.1002/1096-987X(20010130)22:2<178::AID-JCC5>3.0.CO;2-\#.

[41] S. Vyazovkin, C.A. Wight, Isothermal and Nonisothermal Reaction Kinetics in Solids: In Search of Ways toward Consensus, J. Phys. Chem. A. 101 (1997) 8279-8284. doi:10.1021/jp971889h.

[42] S. Vyazovkin, Thermal analysis., Anal. Chem. 82 (2010) 4936-49. 
doi:10.1021/ac100859s.

[43] H.E. Kissinger, Reaction Kinetics in Differential Thermal Analysis, Anal. Chem. 29 (1957) 1702-1706. doi:10.1021/ac60131a045.

[44] M. Brown, D. Dollimore, A. Galwey, Theory of Solid State Reaction Kinetics, in: C.H. Bamford, C.F.H. Tipper (Eds.), Compr. Chem. Kinet. Vol 22, React. Solid State, Elsevier, Amsterdam, 1980: pp. 41-113. doi:10.1016/S00698040(08)70384-4.

[45] J. Šesták, Thermophysical properties of solids, their measurements and theoretical analysis, Elsevier, Amsterdam, 1984.

[46] C. Kittel, H. Kroemer, Thermal Physics, 2nd ed., W. H. Freeman, New York, 1980.

[47] R. Baierlein, Thermal Physics, Cambridge University Press, Cambridge, 1999. doi:10.1017/CBO9780511840227.

[48] J.S. Chickos, W.E. Acree, Enthalpies of Vaporization of Organic and Organometallic Compounds, 1880-2002, J. Phys. Chem. Ref. Data. 32 (2003) 519-878. doi:10.1063/1.1529214.

[49] David R. Lide, CRC Handbook of Chemistry and Physics, 76th edition, 84th ed., CRC Press, Boca Raton, Florida, 2003. doi:10.1136/oem.53.7.504.

[50] O.C. Bridgeman, E.W. Aldrich, Vapor Pressure Tables for Water, J. Heat Transfer. 86 (1964) 279. doi:10.1115/1.3687121.

[51] H.A. Schwarz, Chain decomposition of aqueous triethanolamine, J. Phys. Chem. 86 (1982) 3431-3435. doi:10.1021/j100214a033.

[52] J.R. Welty, C.E. Wicks, G.L. Rorrer, R.E. Wilson, Fundamentals of momentum, heat, and mass transfer, 5th ed., John Wiley and Sons Ltd, Danvers, 2008.

[53] E.N. Fuller, P.D. Schettler, J.C. Giddings, New Method For Prediction Of Binary Gas-Phase Diffusion Coefficients, Ind. Eng. Chem. 58 (1966) 18-27. doi:10.1021/ie50677a007.

[54] R.A. McDonald, S.A. Shrader, D.R. Stull, Vapor Pressures and Freezing Points of Thirty Pure Organic Compounds., J. Chem. Eng. Data. 4 (1959) 311-313. doi:10.1021/je60004a009.

[55] R.M. Stephenson, S. Malanowski, Handbook of the Thermodynamics of Organic Compounds, Springer Netherlands, Dordrecht, 1987. doi:10.1007/978-94-0093173-2.

[56] The Dow Chemical Company, Monoethanolamine, Diethanolamine, 
Triethanolamine, Dow Chem. Co. (2003) 1-21.

http://msdssearch.dow.com/PublishedLiteratureDOWCOM/dh_017d/0901b8038

017d302.pdf?filepath=amines/pdfs/noreg/111-01375.pdf\&fromPage=GetDoc.

[57] C. Minadakis, R. Sabbah, Thermodynamique de composes azotes. VIII. Etude thermochimique de la diethanolamine et de la triethanolamine et de la reaction de reduction de l'eau par celle-cl, Thermochim. Acta. 55 (1982) 147-159. doi:10.1016/0040-6031(82)85149-6. 
Table 1. Assignments of TEA IR absorption frequencies between 900 and $4000 \mathrm{~cm}^{-1}$.

\begin{tabular}{ll}
\hline Wavenumber $\mathrm{cm}^{-1}$ & Assignment \\
\hline 1040 & Stretching C-N \\
1074 & Stretching C-O \\
1158 & Bending $-\mathrm{CH}_{2}-$ and $-\mathrm{O}-\mathrm{H}$ \\
1213 & Bending $-\mathrm{O}-\mathrm{H}$ \\
1297 & Bending $-\mathrm{O}-\mathrm{H}$ \\
1359 & Bending $-\mathrm{CH}_{2-}$ \\
1397 & Bending $-\mathrm{CH}_{2-}$ \\
1458 & Bending $-\mathrm{CH}_{2}-$ (scissoring) \\
2822 & Stretching C-H \\
2885 & Stretching C-H \\
2955 & Stretching C-H \\
3558 & Stretching O-H \\
3673 & Stretching O-H \\
\hline
\end{tabular}


Figure captions

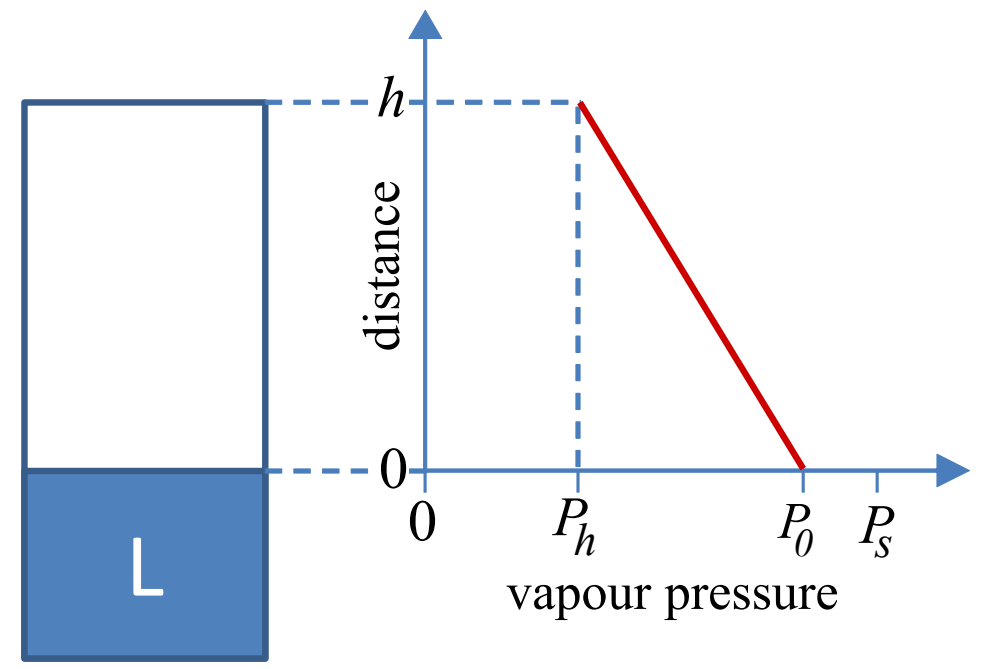

Figure 1. Pressure profile from the liquid film to the open end of the crucible.

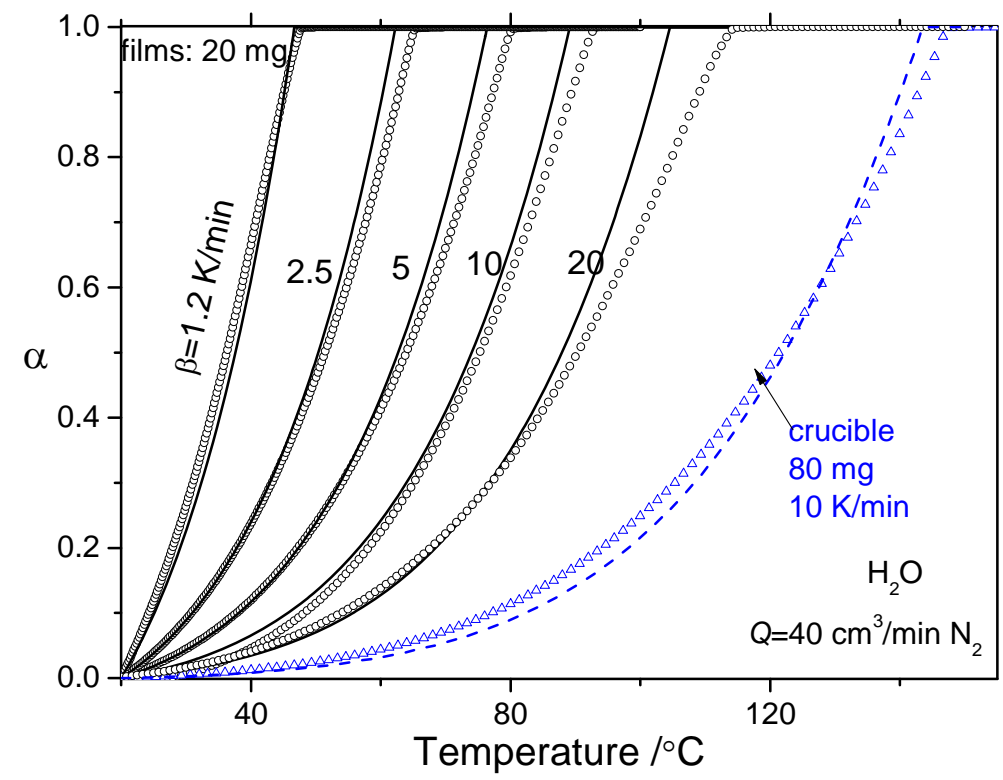

Figure 2. TG analysis of water evaporation in a flowing atmosphere of $40 \mathrm{~cm}^{3} / \mathrm{min}$ of $\mathrm{N}_{2}$. Points: experiment. Curves: simulated evolution according Eq. (25) (films) and to Eq. (24) (crucibles). 


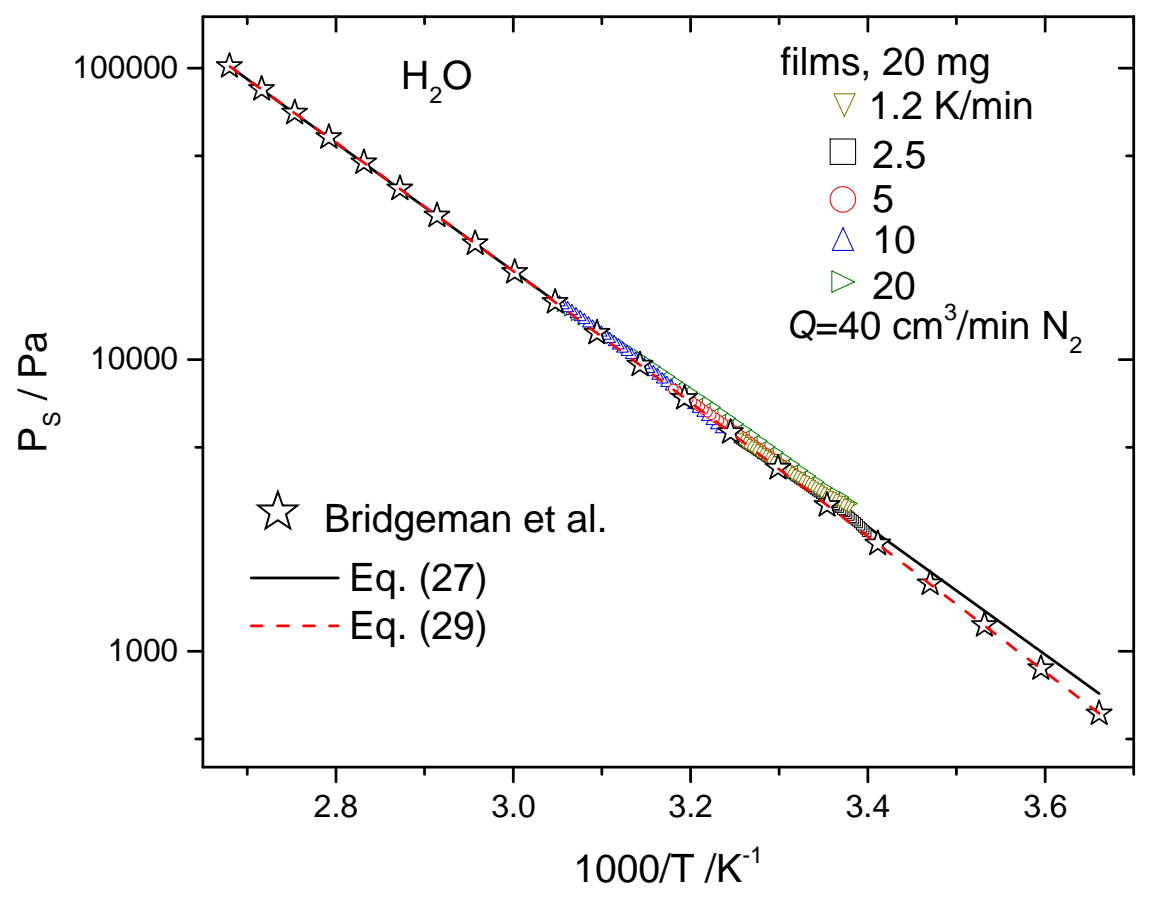

Figure 3. Dependence on temperature of equilibrium water $P_{S}$. Stars: from ref. [50]. Other symbols: our experiments on films of Figure 2. Solid line: linear fit of our data, Eq. (28). Dashed line: $P_{S}$ determined from the dependence of $H_{v a p}$ on temperature, Eq. (30). 


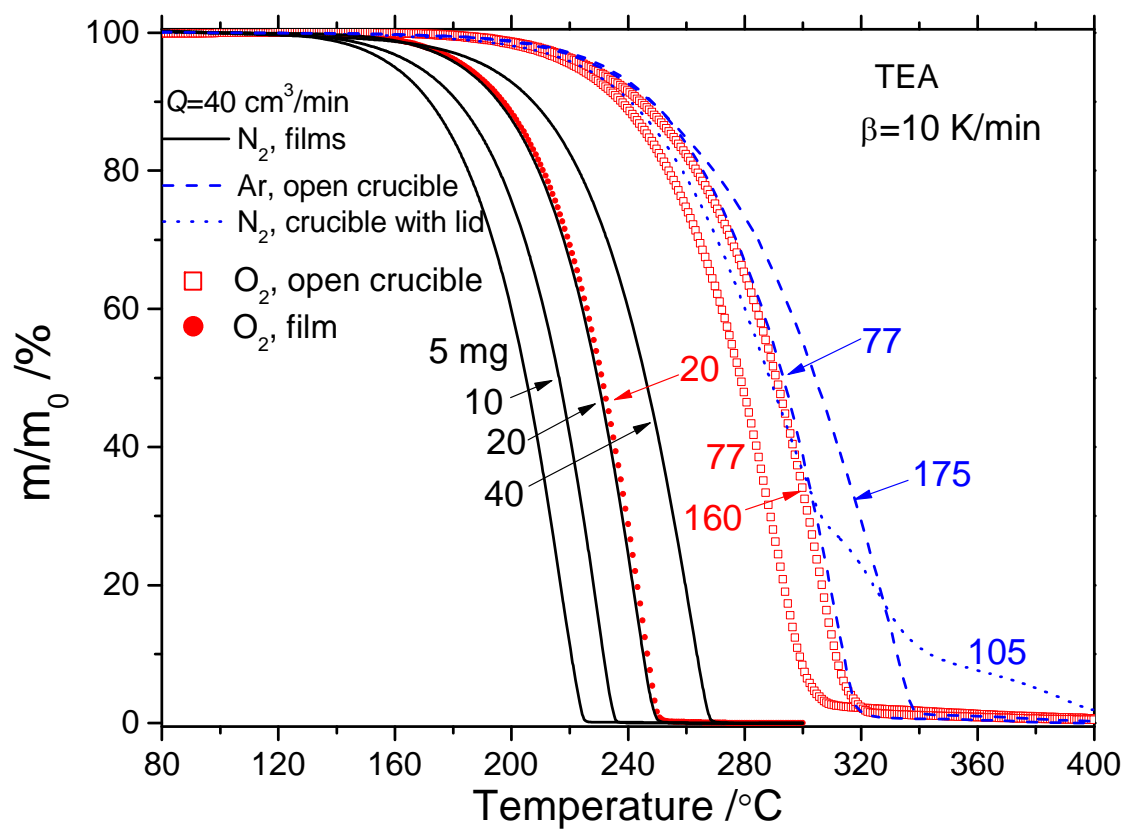

Figure 4. TG analysis of TEA heated at a constant rate of $10 \mathrm{~K} / \mathrm{min}$. 


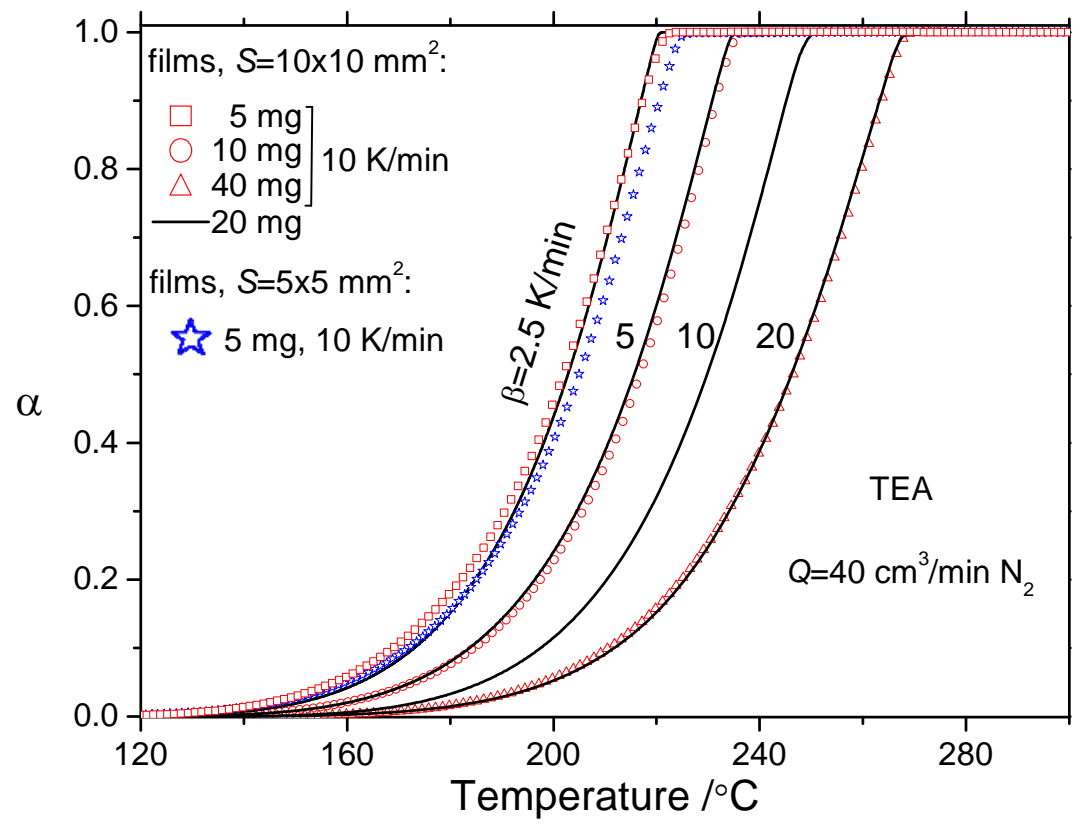

Figure 5. TG analysis of TEA deposited on top of a LAO substrate and under a flow of $40 \mathrm{~cm}^{3} / \mathrm{min}$ of $\mathrm{N}_{2}$. 


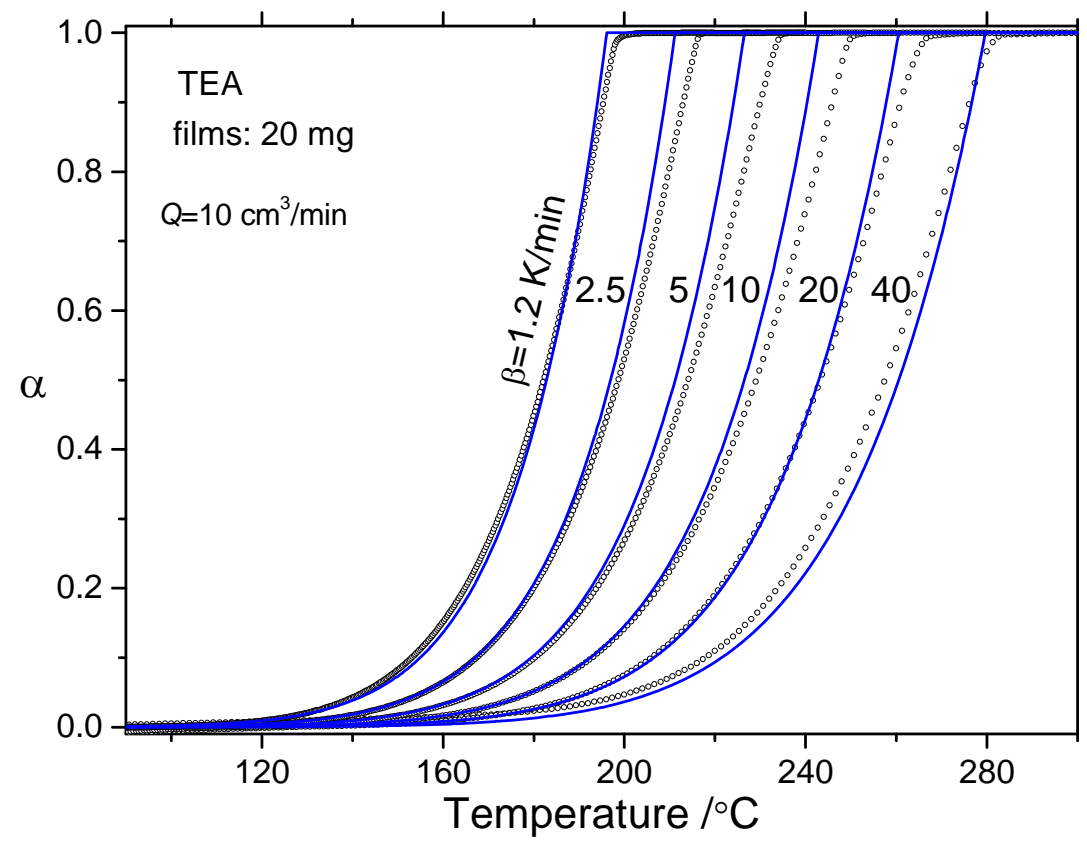

Figure 6. Symbols: experimental TG curves of TEA films deposited on top of a $10 \times 10$ $\mathrm{mm}^{2}$ LAO substrate. Lines: simulation according to Eq. (25) (see main text). 


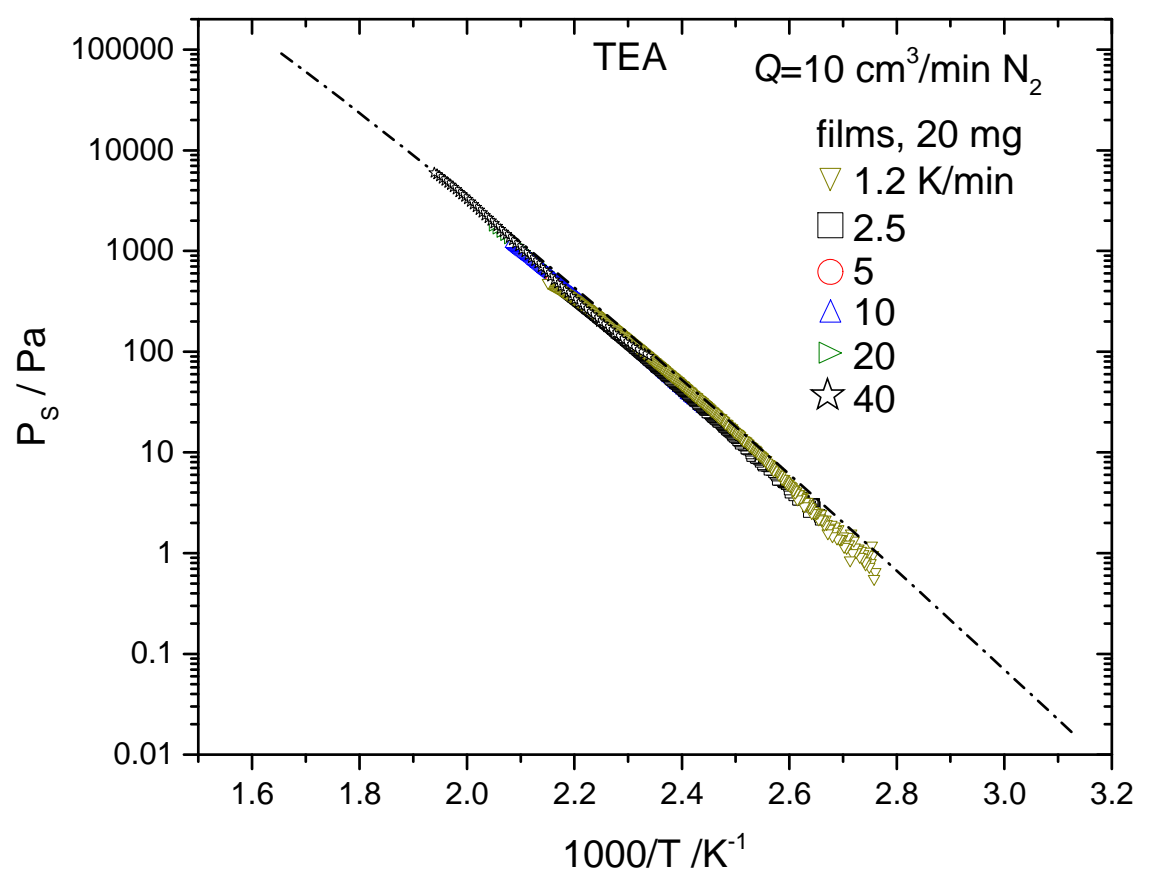

Figure 7. Plot of $\ln \left(P_{S}\right)$ versus $1 / T$ for the experiments shown in Figure 6 (symbols) and the dependence found in the literature (line) (see Appendix B). 


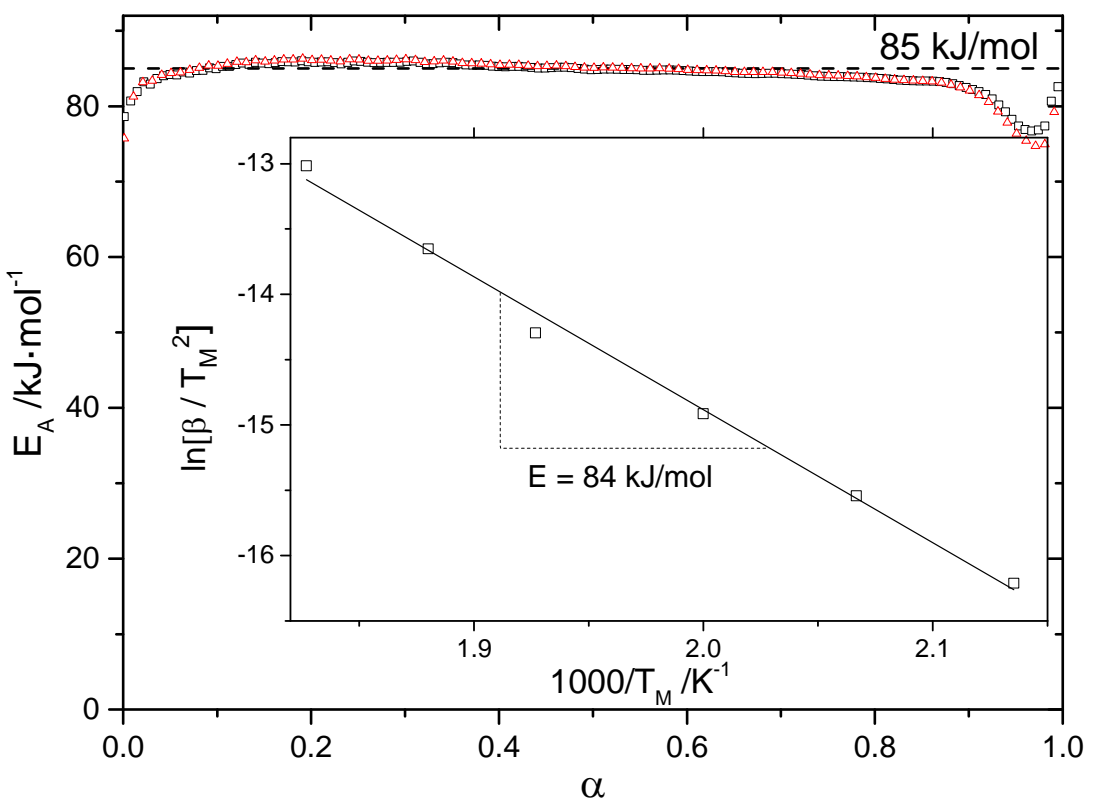

Figure 8. Activation energy determined using advanced isoconversional (squares) and Friedman methods. Inset: Kissinger plot (symbols) and linear fit used to determine the activation energy (solid line). 


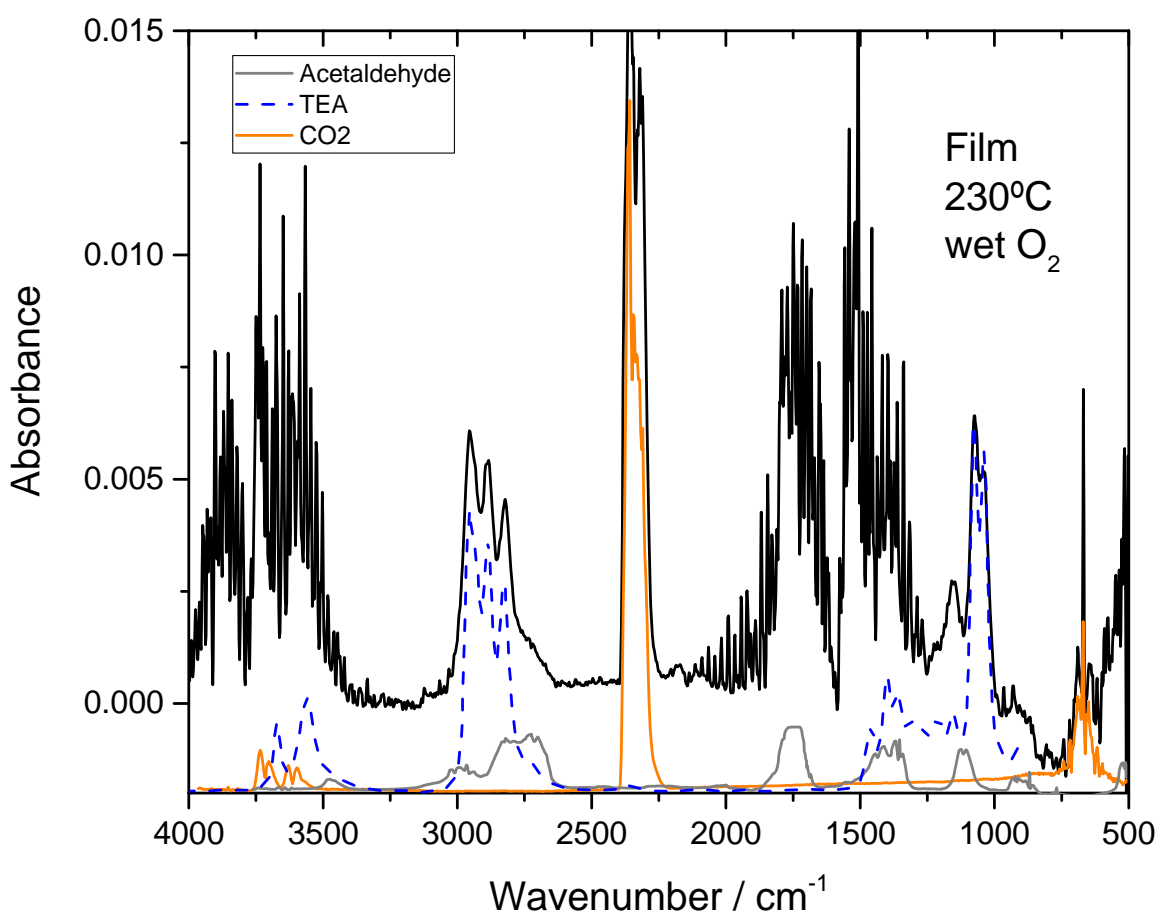

Figure 9. Thick black line (displaced upward): FTIR spectrum of the volatiles evolved at $230^{\circ} \mathrm{C}$ from a TEA film when is heated at a rate of $10 \mathrm{~K} / \mathrm{min}$ under a flow of wet $\mathrm{O}_{2}$. The other lines are reference spectra of TEA, acetaldehyde and $\mathrm{CO}_{2}$ gases. They have been scaled to fit the observed spectrum. 


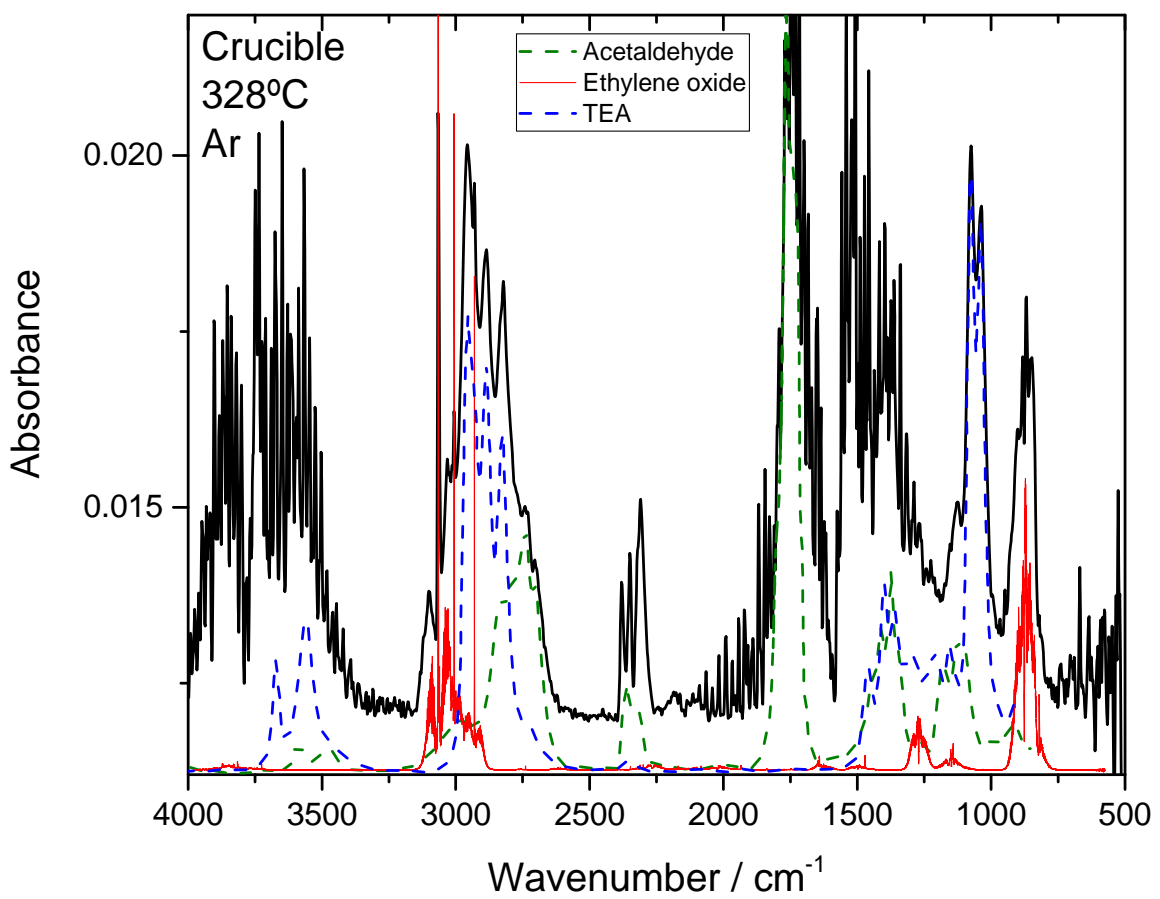

Figure 10. Thick black line: FTIR of the volatiles evolved at $328^{\circ} \mathrm{C}$ from TEA inside a crucible when heated at a rate of $10 \mathrm{~K} / \mathrm{min}$ in argon. The other lines are the spectra of TEA, acetaldehyde and ethylene oxide gases respectively. Reference spectra have been scaled to fit the observed FTIR spectrum. 


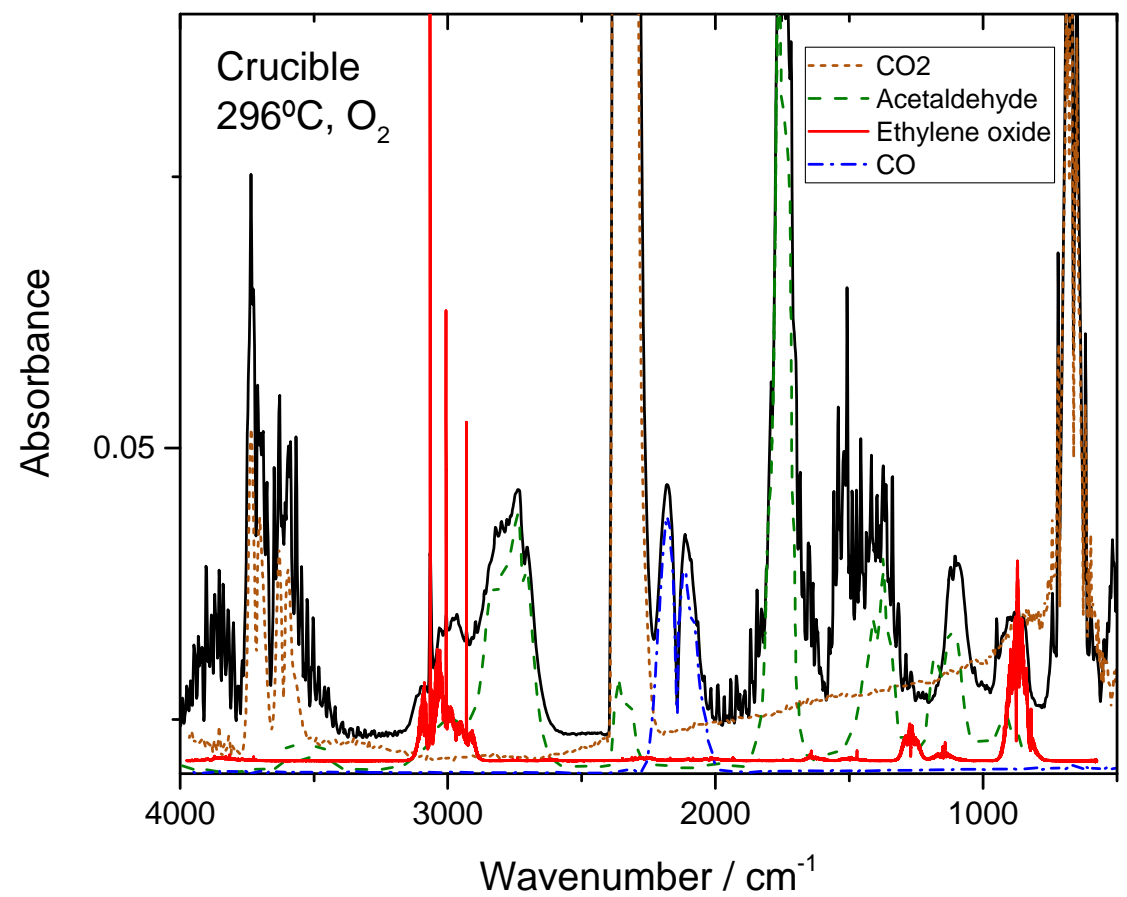

Figure 11. Thick black line: FTIR of the volatiles evolved at $296^{\circ} \mathrm{C}$ from $160 \mathrm{mg}$ of TEA inside a crucible when is heated at a rate of $10 \mathrm{~K} / \mathrm{min}$ under a flow of oxygen. The other lines are the spectra of $\mathrm{CO}_{2}, \mathrm{CO}$, acetaldehyde and ethylene oxide gases respectively. Reference spectra have been scaled to fit the observed FTIR spectrum. 


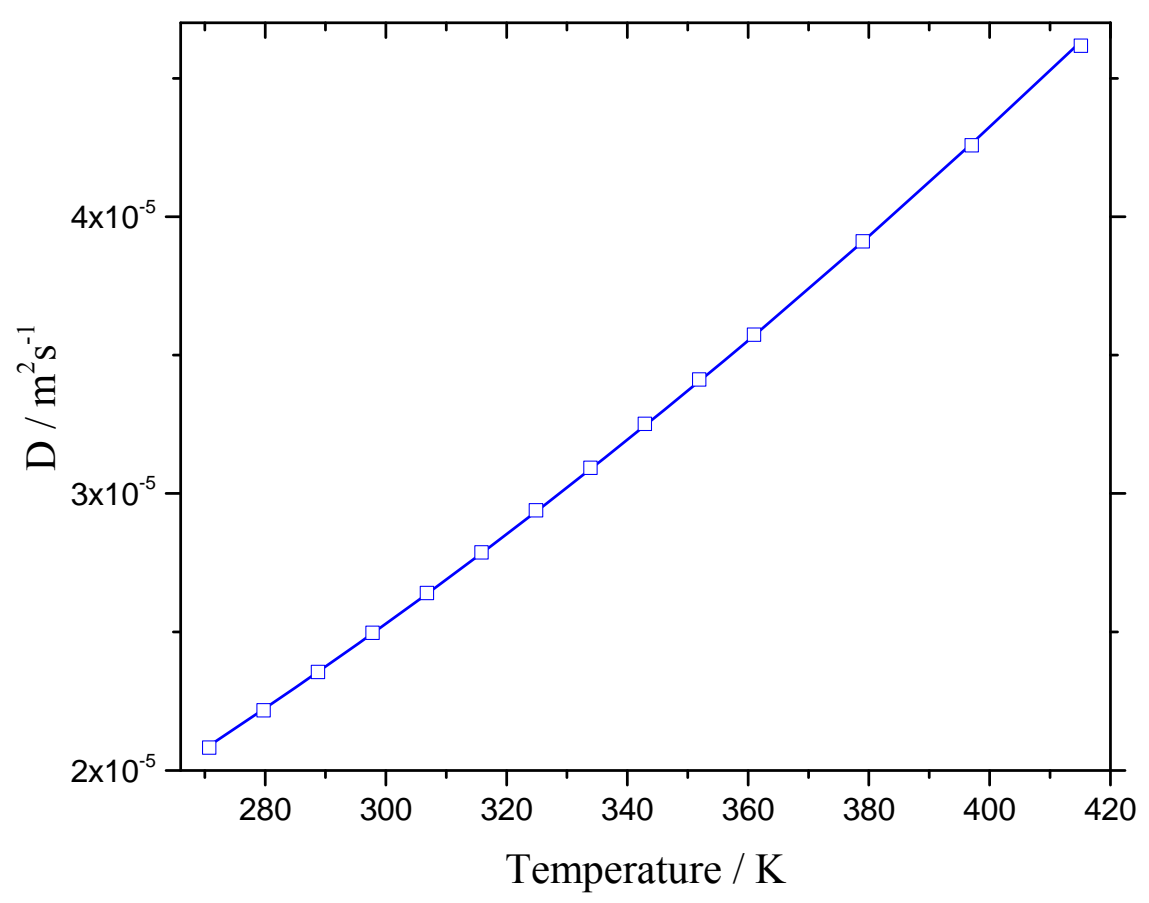

Figure A1. Dependence of the diffusivity of $\mathrm{H}_{2} \mathrm{O}$ in $\mathrm{N}_{2}$ (squares) as a function of the temperature calculated from Eq. (A.1). The solid line is the fitted dependence, Eq. (A.3). 


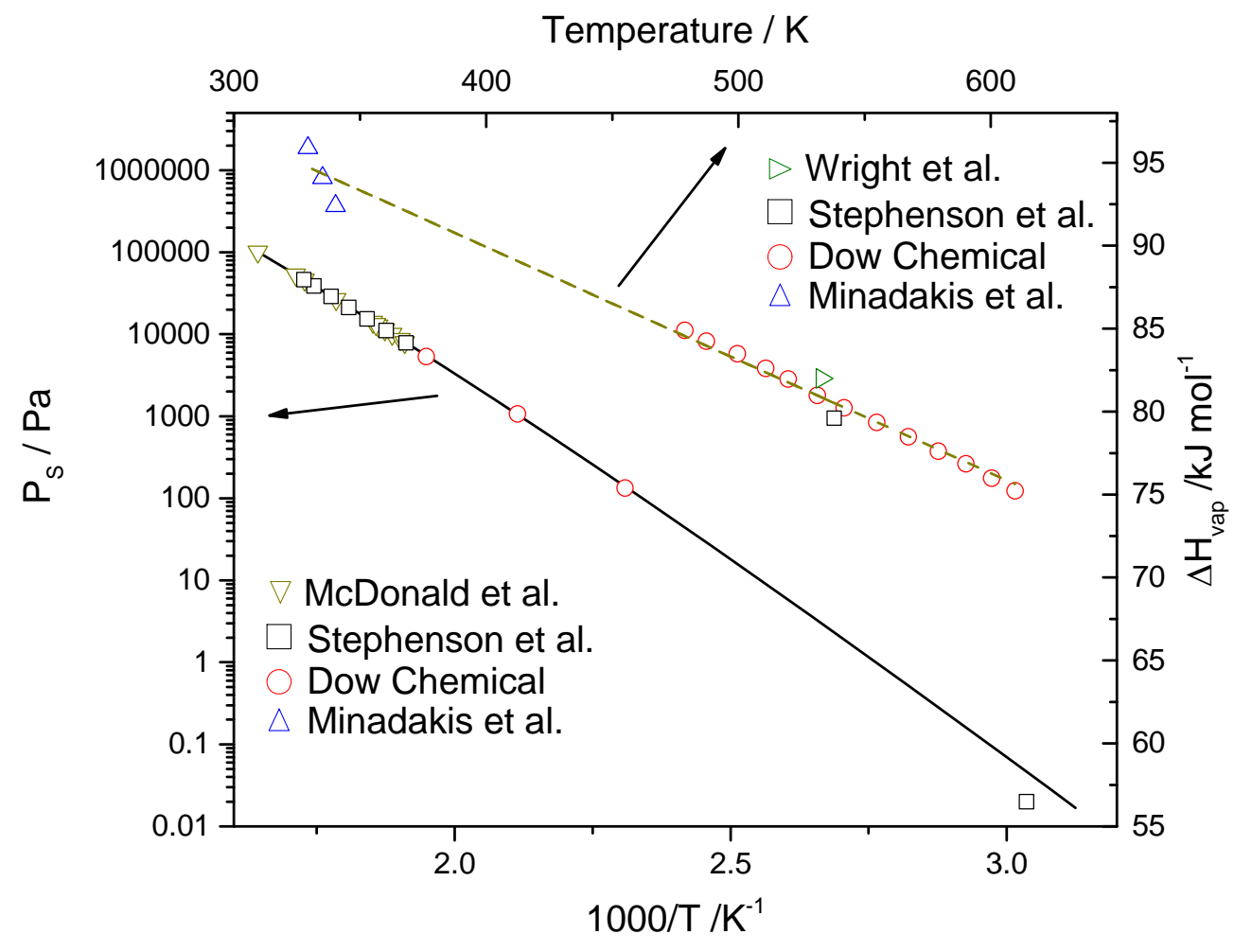

Figure B1. Symbols: values of $P_{S}$ and $\Delta H_{v a p}$ of TEA gathered from different sources. The dashed line is the fitted dependence for $\Delta H_{\text {vap }}$. The solid line is the dependence of $P_{S}$ given by Eq. (30). 


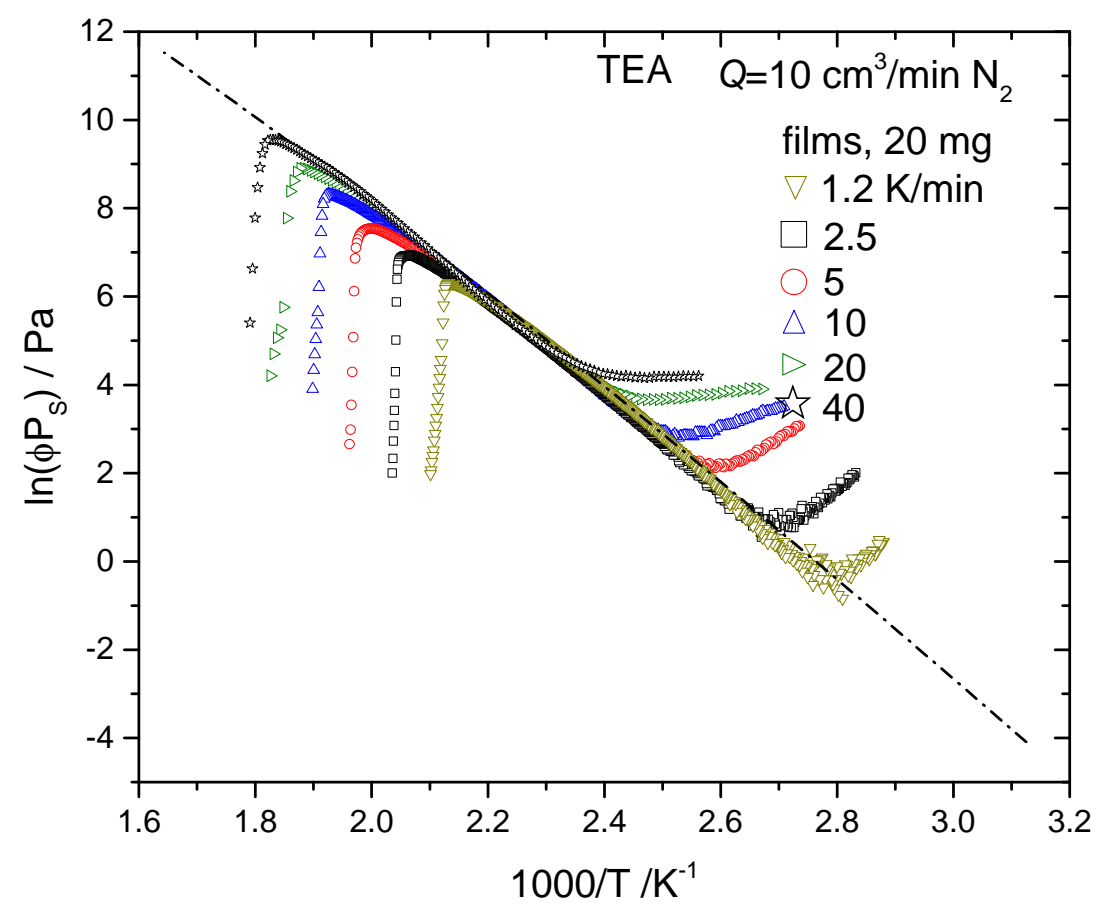

Figure C1. Plot of $\ln \left(-\frac{d m}{d t} \frac{R T}{M Q}\right)$ versus $1 / T$ before removing the points that deviate from the general alignment. 